$9-2013$

\title{
Heterogeneous Response of Disaggregate Inflation to Monetary Policy Regime Change: The Role of Price Stickiness
}

\author{
Chi-Young Choi \\ University of Texas at Arlington \\ Róisín O'Sullivan \\ Smith College, rosulliv@smith.edu
}

Follow this and additional works at: https://scholarworks.smith.edu/eco_facpubs

Part of the Economics Commons

\section{Recommended Citation}

Choi, Chi-Young and O'Sullivan, Róisín, "Heterogeneous Response of Disaggregate Inflation to Monetary Policy Regime Change: The Role of Price Stickiness" (2013). Economics: Faculty Publications, Smith College, Northampton, MA.

https://scholarworks.smith.edu/eco_facpubs/37

This Article has been accepted for inclusion in Economics: Faculty Publications by an authorized administrator of Smith ScholarWorks. For more information, please contact scholarworks@smith.edu 


\title{
Heterogeneous Response of Disaggregate Inflation to Monetary Policy Regime Change: What Can Be Learned from Canada's Adoption of Inflation Targeting?
}

\author{
Chi-Young Choi* \\ University of Texas at Arlington
}

\author{
Róisín O'Sullivan \\ Smith College
}

March 31, 2012

\begin{abstract}
This paper explores the impact of monetary policy regime change on sectoral and regional inflation by analyzing the case of Canada and its adoption of inflation targeting (IT). Using disaggregated CPI data for Canada from 1978, we find that responses to the change in the monetary policy framework are quite heterogeneous, particularly across sectors. While inflation series in the traditionally volatile commodity sectors exhibit weak responses to the regime change, those in the so-called core sectors are highly responsive. This pattern is evident in both national and provincial level data, indicating that it is the core sectors that are crucial for the transmission of a monetary policy regime change. Further analysis based on a common factor model reveals that common shocks, such as those associated with the monetary policy framework, account for only a small portion of the variation in sectoral inflation, and that their relative importance has decreased after IT adoption in many core sectors. Interestingly, considerable variation exists even across the core sectors in the strength of the regime change effect. We document that this heterogeneity is meaningfully correlated with some measurable sector-specific characteristics; sectors with a lower degree of prices stickiness and a lower degree of tradability appear more sensitive to the change in monetary policy regime.
\end{abstract}

Keywords: Monetary policy regime, Inflation Targeting (IT), Heterogeneity, Sectoral inflation, Structural change, Persistence, Factor model analysis, Canadian provinces.

JEL Classification Numbers: E31,E52,E58

\footnotetext{
${ }^{*}$ Corresponding author. E-mail: cychoi@uta.edu. The authors are very grateful to Chris Otrok (co-editor) and two anonymous referees for constructive comments and suggestions that helped to improve the paper greatly. We also benefitted from comments from Roger Kaufman, Dean Scrimgeour, Moto Shintani, Donggyu Sul, Taka Tsuruga, and the session participants at the 10th Econometric Society World Congress in Shanghai and at 2011 AMES meeting in Seoul. We would like to thank Hanzhang Liu and Huong Giang Nguyen for excellent research assistance and Moto Shintani for sharing the data on distribution margins. Any remaining errors are the authors'.
} 


\section{Introduction}

Understanding how changes to the monetary framework might alter the links between policy instruments and goal variables, such as aggregate inflation, has been of great importance for both policy makers and academics. Since national headline inflation is a weighted average of its regional and sectoral subcomponents, a direct way to investigate the impact of a change in the monetary policy regime is to examine the behavior of these subaggregate indices. A notable example of a monetary policy framework change that has become popular in the past two decades is the adoption of Inflation targeting (IT), which aims at stabilizing inflation expectations toward a numerical objective. ${ }^{1}$ Notwithstanding the extensive research on the effects of IT adoption on macroeconomic performance, however, little attention has been paid to how its adoption might impact overall inflation through its subcomponents. In light of ample empirical evidence on sectoral heterogeneity in price dynamics, it is likely that the quantitative effect of IT adoption on subaggregate inflation is very different across sectors. Detailed knowledge of how IT influences the dynamics of subaggregate price indices, therefore, could prove useful to policymakers in a number of ways. For example, it could help policymakers choose an appropriate price statistic for their inflation target by obtaining a better sense of which sectors of the economy might be more affected by policy decisions [e.g. Bryan and Cecchetti 1994, Clark 2001]. It may also allow for a deeper understanding of the welfare costs associated with inflation, which have been often linked in the literature to the variability in relative prices [e.g. Choi 2010, Kryvtsov et al. 2011].

The primary purpose of this study is to analyze the impact of the adoption of IT on the dynamics of inflation across regions and sectors in order to cast light on the channels through which a monetary policy regime change is transmitted to headline inflation. Exploring the responses of sectoral/provincial inflation to the adoption of IT is a worthwhile exercise given the popularity of IT as a monetary framework and the centrality of sectoral heterogeneity to the recent empirical evidence in the literature. Although the importance of sectoral heterogeneity has been recognized in many recent studies [e.g. Carvalho and Nechio, 2011], relatively little attention has been paid to the impact of monetary regime change on the heterogeneity. By tracking the sectoral responses to the monetary regime change, we hope to gain a better understanding of the driving forces behind the heterogeneity in responses across sectors, which is vital for the efficacy of monetary policy. To this end, we use disaggregated consumer price index (CPI) data for Canada and its ten provinces, which is suitable for our analysis on a couple

\footnotetext{
${ }^{1}$ For comprehensive surveys of inflation targeting, see Svensson (2010) and Walsh (2009).
} 
of grounds. First, as an early adopter of IT in 1991, Canada has reasonably long time series of price data with which to examine the post-IT phase. A comparison between the periods before and after IT adoption may provide evidence on whether and indeed how a monetary regime change makes a difference in the dynamics of disaggregate inflation. In addition, the Canadian economy encompasses a diverse range of sectors and comprises distinct provincial regions, with price indices available for 50 subcategories across 10 provinces, enabling a relatively rich disaggregate analysis of the impact of monetary policy framework change.

Our analysis first reveals that monetary regime change has affected inflation in different sectors in different ways. The adoption of IT has had a significant but heterogeneous effect on disaggregate price series, with the heterogeneity more marked across sectors than across regions. While many sectoral inflation rates in the so-called core sectors, which typically include manufacturing goods and services, stabilized within a narrow range around target inflation right after the change in the monetary policy framework, no such pattern is observed in the traditionally volatile commodity sectors, such as those related to food and energy items, where sectoral inflation often fluctuates far outside the target range. As can be seen from Figure 1, which depicts the empirical densities of sectoral inflation before (dotted line) and after (solid line) IT adoption, the distributions of sectoral inflation in core sectors clearly shift to the left after IT adoption, while those of inflation in the commodity sectors show very little movement between the pre- and post-IT periods. A set of structural break tests applied to the disaggregate inflation data tell a broadly similar story, revealing pervasive evidence of a mean shift in many core CPI items around the time of IT adoption, but not for commodity-type products. These findings indicate that the core sectors are the driving force behind the stabilization of the national headline inflation rate in the wake of IT adoption.

This categorical difference is also noted in the effect on inflation persistence which is known to reflect formation of inflation expectations. ${ }^{2}$ While the persistence of inflation is reduced significantly after IT adoption both at the aggregate and disaggregate levels, we observe substantial heterogeneity in the degree of inflation inertia across sectors, with a large number of core sectors experiencing a more marked decline in the intrinsic persistence of inflation after the regime change. Under the IT regime, the persistence in many core-sector inflation series is so low that they are hardly distinguishable from white noise, implying forward-looking formation of expectations. This decline in sectoral inflation persistence is due in large part to the decline in the relative importance of common shocks that are

\footnotetext{
${ }^{2}$ Amano and Murchison (2005) document that the degree of persistence has declined in Canada since the start of IT. Because it is not accompanied by any decline in persistence of the measure of real marginal cost, they conclude that the drop in inflation persistence reflects a change in the formation of expectations.
} 
known to be on average more persistent but less volatile than sector-specific shocks.

Based on a common factor model analysis, we decompose the sectoral inflation series into a common component (driven by common factors) and an idiosyncratic component. We confirm the growing body of evidence in the literature [e.g. Boivin et al. 2009, Maćkowiak et al. 2009] that aggregate common shocks can explain only a small portion of the volatility in sectoral inflation. More importantly, our results suggest that the relative importance of common shocks (dubbed as 'share of common component' throughout the paper) has declined substantially after IT adoption, principally driven by the fall in the variance of common fluctuations in many core sectors. In contrast, the variance of common fluctuations has increased in many commodity sectors. These different responses between core and commodity sectors may stem from the fact that inflation in core sectors responded more sluggishly to aggregate shocks once markets believed that inflation would eventually dampen out as the central bank offsets the effects of exogenous disturbances, while inflation dynamics in non-core sectors remain largely governed by external supply shocks from global market conditions. Given that the dynamics implied by the estimated common factor turn out to track very closely the path of short-run interest rates, we share the view of Boivin et al. (2009) that monetary policy regime change is an important contributor to the volatility reductions in the Canadian sectoral inflation. Beyond the dichotomous behavior of the core and non-core sectors, we find considerable heterogeneity even among core items in their response to the monetary regime change. Although the decrease in the share of the common component is much more prevalent in the core sectors, there exists pervasive evidence on the enormous degree of heterogeneity even among the 33 core sectors, suggesting that IT adoption has exerted a heterogeneous impact on the adjustment of inflation expectations and/or on the price-setting behavior of economic agents across core sectors.

This finding raises an interesting question about what underlying sectoral characteristics might account for the heterogeneity in responsiveness to the policy regime change. Since the adoption of IT constitutes a common macroeconomic shock, we turn to characteristics that vary across sectors and have featured prominently in the literature exploring pricing behavior in order to uncover why this economy-wide shock evoked such a heterogenous response at the sectoral level. Given the central role played by price stickiness in many theoretical models, we first examine the relationship between the degree of price flexibility in the various sectors and the strength of the sectoral response to the adoption of IT. We then explore whether the degree of tradability as emphasized by the Balassa-Samuelson hypothesis holds any explanatory power for the pattern of heterogeneity we observe. Limited availability of sectoral data in Canada for many of these variables led us to utilize comparable data sets for the 
U.S. in the belief that the variation across sectors for the U.S. is a reasonable proxy for that in Canada due to the relatively high degree of integration between the two economies. We find that sectors with a higher degree of price flexibility and a higher degree of tradability appear more sensitive to the change in monetary policy regime. Our results are in line with the findings from previous studies such as Boivin et al. (2009), who have reported industry characteristics to be informative about differences across sectors in the behavior of prices for the US.

Our results therefore highlight another angle to the debate about the appropriate measure of inflation for monetary policy to target. Given the stronger impact of the monetary framework change on core sectors, our main findings appear in line with much of the theoretical literature [e.g. Aoki 2001, Clarida et al. 2002, Eusepi et al. 2011, Huang and Liu 2005] that favors a core measure of inflation over headline CPI as the welfare-maximizing goal variable. ${ }^{3}$ However, because these theoretical models rely on a number of strong underlying assumptions that are easily violated in reality, such as representative products and complete financial markets, and because substantial heterogeneity exists even among core sectors, one must exercise caution in interpreting our results as supportive evidence of those theoretical models based on a dichotomous approach. ${ }^{4}$

The remainder of the paper is laid out as follows. Section 2 describes the data and provides a preliminary analysis of the heterogenous patterns in the subaggregate series. Section 3 extends this analysis using more formal econometric techniques, including structural break tests, an inflation persistence measure, and common factor model analysis. This is followed in Section 4 by an analysis of the potential sources of the heterogeneity we observe. Section 5 concludes the paper. The Appendix contains a detailed description of the data.

\section{The data and preliminary analysis}

We use monthly indices of the overall consumer price index and its subcomponents at both the national level and for ten provinces in Canada: Alberta (ALB), British Columbia (BCA), Manitoba (MAN),

\footnotetext{
${ }^{3}$ However, more recent studies based on more realistic assumptions, such as Anand and Prasad (2010) in an incomplete (financial) markets setting and de Resende et al. (2010) in the presence of sector-specific real rigidities, assert that a welfare-maximizing central bank should adopt a target based on headline rather than core inflation.

${ }^{4}$ As noted by Ambler (2009), another serious issue embedded in the current generation theoretical models in the analysis of the effectiveness of monetary policy regime changes is potential vulnerability to the Lucas Critique. Even with an ideal theoretical model that accommodates all the attractive features, it is still challenging to trace the effect of the monetary regime change within the standard theoretical framework because some key components of models, such as the degree of nominal rigidity, are assumed to be constant. Any comparison of social welfare across monetary policy regimes based on those theoretical models therefore can potentially yield seriously misleading results. As a notable exception to this issue, Kimura and Kurozumi (2010) recently developed a New Keynesian Phillips curve (NKPC) model that endogenizes nominal rigidities across monetary policy regimes.
} 
New Brunswick (NBW), Newfoundland (NFL), Nova Scotia (NSC), Ontario (ONT), Prince Edward Island (PEI), Quebec (QUB), and Saskatchewan (SAS). Of the 118 sectoral price indices available at various levels of aggregation, we focus on those at the most disaggregate level. ${ }^{5}$ Table A.1 in the Appendix presents the 50 sectors for which monthly price indices are available from September 1978 until May 2010, resulting in 381 observations for each series. The table contains weights for each of the 50 items that together comprise approximately 75 percent of the CPI. There is, however, substantial variation in the weights allocated to each sector, ranging from $0.14-0.18 \%$ for 'Fats and oils' to 5.36$7.75 \%$ for 'Rented accommodation'. Moreover, the weights also vary slightly across provinces and over time. Inflation is calculated as the annualized monthly percentage change in the consumer price index, after seasonally adjusting the price indices using the Census X12-ARIMA method.

Table 1 presents summary statistics (mean, 10 and 90 percentiles, and standard deviation) on national inflation across sectors for the full sample period and for three subsample periods, using 1983:M8 and 1991:M2 as breakpoints. ${ }^{6}$ Table 1 shows considerable variation in the mean and volatility of sectoral inflation. In the full sample period, for instance, the annualized average inflation rate ranges from $-0.75 \%$ for 'Recreational equipment and services' to $8.63 \%$ for 'Tobacco products'. Volatility, measured by standard deviation, also exhibits similar sectoral heterogeneity, varying between 2.13 ('Rented accommodation') and 18.24 ('Fuel oil'). It is worth noting that sectoral inflation is higher than the headline inflation rate in 25 of 50 sectors but more volatile than headline inflation in the vast majority of sectors (44 out of 50 sectors). Qualitatively similar results hold for each subsample period under study.

Interestingly, looking across subsamples, it appears that the Great Moderation and the adoption of IT had different impacts on sectoral inflation dynamics. While the reduction in both the mean and volatility of inflation occurred almost uniformly across all sectors in the Great Moderation beginning in 1983, such a decline is noticed in the mean but not in the volatility of sectoral inflation under the IT regime. The volatility of sectoral inflation actually increased after the IT adoption in many sectors, as well as in headline inflation. This seems rather surprising in light of the ample empirical

\footnotetext{
${ }^{5}$ The selection of sectors was mainly governed by the availability of sufficiently long continuous data series for monthly price indices. For some sectors in which price indices are available at this level of disaggregation for only a short period in most provinces, we retain the series at the next highest level of aggregation. ALB has some missing observations for 'Fuel oil and other fuels', BCA for 'Electricity', and PEI for 'City bus and subway transportation' and 'Traveler accommodation'. The underlying data have been collected from Statistics Canada homepage (http://www.statcan.gc.ca/).

${ }^{6}$ September 1983 marks the onset of the so-called Great Moderation when the level and volatility of inflation declined significantly in Canada. February 1991 is the official adoption date of inflation targeting in Canada. The choice of break points is also supported by more formal econometric analysis based on Bai-Perron's multivariate break-point test method outlined in the next section.
} 
evidence on the effect of IT on the reduction in both the mean and volatility of inflation in Canada [e.g. Longworth, 2002]. The disparity, however, can be explained by the difference in the coverage of the pre-IT period. While the existing literature tends to include the Great Inflation (prior to the year 1983 ) in the pre-IT period, we focus only on the Great Moderation period. ${ }^{7}$ Having said that, our unusual finding on the non-decrease in the volatility of many sectoral inflation rates is believed to be mainly driven by the increased role of sector-specific shocks under the IT regime. We revisit this issue in Section 3.2 for further discussion.

To ensure the robustness of our findings to the choice of sample periods, we display the dynamic behavior of sectoral inflation in Canada in Figure 2, which plots the evolution of sectoral inflation (solid line) over time along with the announced target range of inflation (dotted line) adopted by the Bank of Canada since 1991. ${ }^{8}$ Not surprisingly, headline inflation (Item \#1) quickly fell within the intended target range after the adoption of IT, indicating the effectiveness of IT in stabilizing inflation. Such stabilization of inflation, however, is not seen in every sector. Whereas sectoral inflation in some core sectors, largely manufacturing and service sectors, display a similar downward adjustment below the upper bound of the target range around the IT adoption date, no such adjustment is noted in the commodity sectors like food (\#2-15) and energy (\#22, 24 and 34). An essentially similar picture is painted in the upper panel of Figure 3, which portrays the cross-sector correlation of sectoral inflation during the sample period. As can be seen from the plots, the correlations have declined substantially in the early 1990s when the Bank of Canada launched a new monetary policy regime, indicating that the nature of comovement across sectoral inflation, particularly between core and non-core sectors, changed drastically after IT adoption. Taken together, our results corroborate the key prediction of optimizing dynamic general equilibrium models with nominal price stickiness [e.g. Aoki 2001] in that they highlight the relatively greater influence of monetary policy over prices in the core sectors of the economy. ${ }^{9}$

The heterogeneity between core and commodity sectors is also noted at the provincial level, although disaggregate inflation appears to be much less heterogeneous across provinces for each sector.

\footnotetext{
${ }^{7}$ In fact, we could see a notable decline in the volatility of (headline) inflation under the IT regime, once the pre-IT period is extended to include the early 1980s.

${ }^{8}$ The Bank of Canada originally set a target inflation range of $2-4 \%$ which was lowered at the end of 1992 to $1.5-3.5 \%$ until June 1994 when it was re-adjusted to the current range of 1-3\%. Largely similar results are obtained using sectoral inflation rates for each province.

${ }^{9}$ Based on a two-sector dynamic general equilibrium model, with a flexible-price sector and a sticky-price sector, Aoki (2001) demonstrates that the optimal monetary policy is to stabilize core inflation which is identified as an index of inflation in the sticky-price sector. By showing that the welfare costs of inflation are larger in sectors with stickier prices in a simple new Keynesian model of the open economy, Clarida et al. (2002) also maintain that food and energy prices, which display little stickiness, should not be included in the inflation rate the central bank attempts to control.
} 
As can be seen from the lower panel of Figure 3, which plots the evolution of provincial inflation rates for some selected sectors together with aggregate inflation (Item \#1), provincial inflation exhibits a very similar pattern to that of national headline inflation and the sectoral ranking at the national level applies within each province. The aggregate provincial inflation rates have fallen into the targeted range right after the IT adoption and remained within the range afterwards. In each province, however, a sharp difference exists in inflation dynamics across sectors, especially between the core sectors where a significant moderation of inflation can be observed in the wake of IT adoption, and the commodity sectors where prices have remained highly volatile under the IT regime.

Overall, our results strongly suggest that the impact of IT is highly heterogeneous across sectors (though far less across regions), with a clear distinction between core and commodity sectors. To gain further insight into this heterogeneity, we next turn to more formal econometric analysis.

\section{Econometric analysis of the heterogeneity of sectoral inflation}

The descriptive statistics discussed in the previous section show that the adoption of IT has had a significant but heterogeneous impact on inflation dynamics in Canada. Given the limited information in summary statistics, we extend our analysis and use more formal econometric methods. Specifically, we employ (i) structural break tests; (ii) a measure of inflation persistence; and (iii) common factor analysis to investigate further the impact of the change in monetary policy regime.

\subsection{Bai-Perron structural break tests}

Using the popular multiple structural break test developed by Bai and Perron (1998), we first look at whether a regime shift in monetary policy induces any structural shift in the dynamics of sectoral inflation. ${ }^{10}$ Kozicki and Tinsley (2001) maintain that empirical evidence on structural change in the mean of inflation may reflect shifts in economic agent perceptions of the policy target for inflation. Since our graphical analysis in the previous section strongly suggests a differential response across core and commodity sectors, we expect to see a structural change in the core sectors but not necessarily in the commodity sectors around the time of IT adoption.

Figure 4 displays the frequency of estimated structural break points in the inflation series across

\footnotetext{
${ }^{10}$ Break points were identified by applying the sequential multiple breakpoint test of Bai and Perron (1998) to sectoral inflation in all provinces. To be specific, we consider a pure structural change model, $\pi_{t}=\delta^{(j)}+\varepsilon_{t}$, where the breaks are assumed to be in the mean of inflation. Following the guidelines from Bai and Perron, the break is assumed not to occur during the initial $15 \%$ nor the final $15 \%$ of the sample period in testing for structural breaks. The maximum number of breaks is set to five and the minimum regime size is set to $5 \%$ of the sample. Robust standard errors are based on a quadratic spectral kernel HAC estimator with $\mathrm{AR}(1)$ prewhitening filters.
} 
the 50 sectors for each province and at the national level. The timing of the break points is very similar across provinces and two dominant break points emerge: the first occurs around 1983, which is widely accepted to represent the onset of the Great Moderation, and the second around 1990-1991, coinciding with the official adoption of IT. ${ }^{11}$ The outcome of the tests therefore support the choice of break points used in the previous section. Comparing the frequency of the two break points, we note that the 1983 break point occurs in more sectors in the national data and in four of the provinces (ALB, BCA, NFL, and PEI), while the 1991 break point is dominant in five provinces (MAN, NBW, NSC, QUB, and SAS). Interestingly, in the largest province, ONT, which accounts for about $40 \%$ of the Canadian economy, the two break points appear to be equally frequent.

Table 2 reports the estimated dates for the structural breaks for each sector. At the aggregate level, each individual province appears to have experienced breaks at similar dates in 1983 and 1991, with a narrow cross-province variation of 1983:05-1983:08 for the first break and 1990:12-1991:10 for the second break. ${ }^{12}$ Second and more important, not all sectoral inflation series experienced a structural break. This is particularly the case for the 17 commodity sectors, with hardly any breaks found for 13 sectors. More importantly, no structural break is observed for any of the commodity sectors around the time of IT adoption, indicating no response to the change in monetary regime. This can be explained by the fact that commodities are typically traded in standardized and highly competitive global auction markets due to their homogeneous nature [e.g. Rauch 1999] and thus their price dynamics are dominated by developments in these global markets rather than by decisions about monetary policy in any individual country. By contrast, strong evidence of structural change is found in many core sectors, especially around 1983 and 1990-1991. Among the core sectors, we see that 17 sectors had a structural break around 1991 at the national level and 24 sectors had a break in at least

\footnotetext{
${ }^{11}$ Other notable economic events that took place around 1990-1991 include a minor global oil price shock, a recession in Canada, and the introduction of the Goods and Services tax (GST) in Canada on January 1, 1991. Among them, we give special consideration to the introduction of GST as a potential source of the structural changes in sectoral inflation. We do not believe, however, the structural breaks in 1990-1 are attributable (at least solely) to the introduction of GST, partly because it would have exerted upward pressure on the mean inflation rather than the downward pressure exhibited in the data. As clearly stated in the lecture (October, 1998) of then Governor of the Bank of Canada, Gordon Thiessen, '[t]he key objectives of Canada's inflation targets, when they were originally announced in 1991, were to prevent inflation from accelerating in the short run in the face of the introduction of the new Goods and Services Tax (GST) and a sharp rise in oil prices and, in the longer run, to bring inflation down to a level consistent with price stability.' Given the downward shift in the mean inflation, the evidence on structural change is believed to be driven by the monetary policy regime change rather than by the introduction of the GST. Besides, some CPI sectors that were exempt from GST (e.g. items \#17, 37, and 39) still experienced a structural change in 1990-1991, while no evidence of a structural break is found for other sectors that were subject to GST (e.g. items \#12, 15, 22 and 34).

${ }^{12}$ The timing of the second break in the national headline inflation (1990:12) slightly precedes the formal announcement dates of IT adoption (1991:02). Such a short time lead may reflect an adjustment of inflation expectations and pricing behavior by the public prior to the official adoption date.
} 
one province.

In sum, our results from the Bai-Perron multiple structural break tests support strongly the heterogeneous responses across core and commodity sectors to the monetary regime change. Since the evidence of structural change around the adoption of IT is found primarily in the core sectors, monetary policy's effect is believed to have been transmitted to headline inflation mainly through these core sector prices.

\subsection{Persistence of sectoral inflation}

Another important mechanism through which monetary policy regime change affects sectoral inflation must be inflation persistence. As often documented in the literature [e.g. Cecchetti et al. 2009, Walsh 2009] a key anticipated benefit of the adoption of IT is better-anchored inflation expectations and anchoring long-run inflation expectations is known to be reflected in inflation persistence. A vast empirical literature has shown that changes in the monetary policy regime affect not only the mean of inflation but the persistence of the inflation process [e.g. Altissimo et al. 2006, Benati 2008, Levin and Piger 2004, Ravenna 2006, Roberts 2006]. They commonly find lower persistence in inflation dynamics once the identified breaks are accounted for. Benati (2008), for example, studied a number of industrialized countries, including Canada, and found a notable fall in inflation persistence in all the countries that have adopted an IT regime. Since inflation persistence is known to reflect the formation of inflation expectations, such a decline in persistence under IT regime is often attributed to a quick transition of inflation expectations formation from backward-looking indexation to a forwardlooking mechanism after the establishment of a clearly defined nominal anchor [e.g. Erceg and Levin 2003, Orphanides and Williams 2005]. While much of the existing research is concerned with the persistence of aggregate inflation, a growing literature at the disaggregate level, including Bilke (2005) and Altissimo et al. (2009), uncovers the presence of widely different degrees of inflation inertia across sectors, with sectoral rates generally exhibiting a much lower degree of inertia than their aggregate counterpart. ${ }^{13}$ The presence of widespread heterogeneity in the persistence of sectoral inflation has important policy implications not just because it implies different responses across sectors to the monetary policy regime change, but because it affects the design of the target inflation measure due

\footnotetext{
${ }^{13}$ Using disaggregated CPI data for France, for instance, Bilke (2005) found significant sectoral differences in inflation persistence, with inflation in the services and industrial goods sectors more persistent than the food and energy sectors, although a pronounced decline is observed in both aggregate and sectoral inflation persistence once the shifts in mean inflation due to the monetary policy regime change are taken into account. The higher persistence of aggregate inflation series may stem either from aggregation bias or from an aggregation process that removes counteracting effects of idiosyncratic shocks.
} 
to different anchoring of inflation expectations across sectors.

In this section, we evaluate the extent to which IT exerts a measurable influence on inflation persistence. We first measure the reduced-form (intrinsic) persistence of each inflation series using the sum of autoregressive coefficients (SARC) in the $\mathrm{AR}(\mathrm{p})$ representation of

$$
\pi_{t}=\beta_{0}+\sum_{j=1}^{p} \beta_{j} \pi_{t-j}+\varepsilon_{t}=\alpha+\rho \pi_{t-1}+\sum_{k=1}^{p-1} \zeta_{k} \Delta \pi_{t-k}+\varepsilon_{t}
$$

where $\rho=\sum_{j=1}^{p} \beta_{j}$ denotes the SARC and the lag length $(p)$ is selected using BIC with a maximum lag length of 8 . To deal with the well-known downward small sample bias embedded in the OLS estimation of $\rho$, we follow the common practice in previous studies [e.g. Benati 2008, Clark 2006] and employ the Hansen's (1999) 'grid bootstrap' based median-unbiased (MUB) estimator. It should be noted that we use quarterly data here, which were computed by averaging the monthly indices for the three months in the quarter as in Stock and Watson (2007). ${ }^{14}$

Table 3 presents MUB estimates of $\rho$ by sector for both the full sample and the two subsample periods, along with the $90 \%$ confidence intervals. Several important features emerge from this table. First, the aggregate inflation rate displays greater persistence than its disaggregate components with the exception of a handful of core sectors $(\# 17,37,40)$, confirming the stylized fact established in the literature. Columns 2-3 of the table show that the MUB estimate for headline inflation is as high as 0.95 in the full sample, with the corresponding upper limit of the $90 \%$ confidence interval exceeding unity. Moreover, the inflation persistence varies substantially across sectors. While it lies above 0.90 in six core sectors, it is below zero in some commodity sectors. As such, inflation in the commodity sectors are in general less persistent than their core sector counterparts. This lower inflation persistence observed in the commodity sectors not only reflect the characteristics of commodity markets in which prices are determined by ever-changing global market conditions, but also indicate the lesser scope for national monetary policy decisions to influence price dynamics in these sectors.

Furthermore, inflation persistence exhibits a significant fall after the adoption of IT as the MUB estimates have declined substantially in the vast majority of sectors (38 out of 50 sectors) as well as

\footnotetext{
${ }^{14}$ When month-to-month inflation rates are used, we notice that the SARC estimates take large negative values in many sectors, especially in the post-IT subsample period, making comparison of inflation persistence based on SARC difficult. Interestingly, a similar negative serial correlation is reported by Benati (2008) in the U.K. inflation rates after IT adoption, who interpreted this negativity of SARC as evidence against backward-looking indexation under the IT regime. The large negative values of SARC estimates could also have resulted from over-differencing of sectoral prices that are close to $\mathrm{I}(0)$ while the aggregate price index is still $\mathrm{I}(1)$. In this case, taking a first difference for the stationary sectoral prices results in an $\mathrm{I}(-1)$ or MA unit root process with an MA coefficient of, say $\theta$. The SARC for an MA(1) process is then given by $\left[1-\frac{1}{(1+\theta)}\right]$ which will take a negative value when $\theta<0$ and will diverge to negative infinity if $\theta$ approaches -1 .
} 
in headline inflation. The fall is particularly noticeable for headline inflation with the MUB estimate dropping drastically from 0.93 to 0.26 , supporting the popular view that anchoring inflation to an explicit objective induces less persistence in the inflation process. This implies that IT was successful at anchoring expectations by dampening the impact of shocks that might otherwise have initiated a persistent departure of inflation from the target value. Sectoral inflation also exhibits markedly lower persistence under the IT regime and the MUB estimates are below 0.3 in 19 sectors, indicative of the near white-noiseness of sectoral inflation rates. ${ }^{15}$ Not surprisingly, the decline in inflation persistence differs considerably across sectors. Although we fail to notice any systematic difference between commodity and core categories, as the MUB has decreased in both categories, on average the core sectors appear to have experienced more significant declines in persistence. Figure 5 displays the persistence of sectoral inflation for a rolling window of 12 years. Note that in many cases, including for aggregate inflation (item \#1), inflation persistence fell sharply around 1990 when IT was adopted. Such structural change in the persistence measure, however, is noted mostly in core sectors, suggesting that the persistence decline in the aggregate inflation was mainly driven by those core sectors. Given that a better anchoring of expectations is widely recognized as the main benefit of adopting IT at the aggregate level, our results suggest that the benefit does not seem present in all sectoral inflation series.

Table 3 also reports the breakdown of inflation persistence into common and idiosyncratic (sectorspecific) components across all sectors. The results are obtained from applying our persistence measure to sectoral inflation that is decomposed into aggregate and sector-specific components as stipulated in the following section. They are generally consistent with the existing evidence in the literature that the common component is far more persistent than the idiosyncratic component in most cases. ${ }^{16}$ The persistence in many sectoral inflation series is therefore largely propagated by the persistence in the common component. Despite the non-negligible differences across sectors, the speed of response to idiosyncratic shocks in general is very low and it appears indistinguishable from white noise in many sectors as it is close to or below zero even prior to the IT adoption. More importantly, the persistence

\footnotetext{
${ }^{15}$ This supports the claim by Roberts (2006) that the long-run consequences of a policy of a fixed inflation target is inflation that is not only stationary but serially uncorrelated. He also found that many sectoral inflation rates in Canada appear indistinguishable from white noise after IT adoption.

${ }^{16}$ As well established in the literature, disaggregated sectoral inflation series are on average more volatile and less persistent than their aggregate counterpart. Boivin et al. (2009) show that sectoral prices are sticky in response to common shocks while being flexible to sector-specific shocks, and that in most cases sectoral inflation persistence is due in large part to fluctuations in common factors, whereas idiosyncratic components display, on average, almost no persistence. The persistence of the aggregate inflation rates thus reflects the persistence of the common component in disaggregated inflation, as the idiosyncratic components tend to average out across sectors. Altissimo et al. (2009) also found similar results using disaggregated CPI inflation series in Europe.
} 
in the common component has dropped significantly after IT adoption, from 0.75 to 0.26 . Since we fail to notice any drastic change in the persistence of the idiosyncratic component, the decline in persistence in sectoral inflation is believed to be mainly driven by the decrease in common component persistence.

\subsection{Common factor model analysis}

It is generally maintained that the variance of sectoral inflation can be decomposed into two components: one which is common to all sectoral inflation rates driven by aggregate economic shocks such as monetary policy, and the other driven by idiosyncratic shocks that are specific to each sector. A growing empirical literature [e.g. Boivin et al., 2009] suggests that the variance of sectoral inflation is attributable more to sector-specific shocks than to common aggregate shocks. ${ }^{17}$ Given that monetary policy changes are associated with common shocks, monetary regime change would affect the dynamics of sectoral inflation mainly through common components. Initial intuition seems to suggest that IT adoption reduces the role of the common component in explaining sectoral inflation fluctuations. This is because, once inflation expectations are anchored under IT, sectoral inflation would respond more sluggishly to aggregate shocks, as markets would expect the associated inflation to eventually dampen out with central bank policy offsetting the effects of exogenous disturbances. To gain further insight into this issue, we follow much of the literature and employ a common factor model that has become popular in macroeconomic modeling and policy analysis [e.g. Bernanke et al. 2005, Boivin et al. 2009]. By decomposing the fluctuations in sectoral inflation into a common and a sector-specific (idiosyncratic) component, we can formally assess the relative importance of the monetary policy regime change that constitutes an economy-wide macroeconomic shock.

We consider the following prototypical factor representation,

$$
\pi_{i t}=a_{i}+C_{i t}+e_{i t}=a_{i}+\lambda_{i}^{\prime} F_{t}+e_{i t}
$$

where $\pi_{i t}$ denotes the inflation rate in sector $i$ in period $t, a_{i}$ represents an individual fixed effect, $C_{i t}$ is common component, and $e_{i t}$ is an idiosyncratic error associated with idiosyncratic sectoral events or measurement error. Note that the common component $\left(C_{i t}\right)$ is the product of $F_{t}$ and $\lambda_{i}$, where the

\footnotetext{
${ }^{17}$ Using U.S. PCE data, Boivin et al. (2009) find that macroeconomic fluctuations explain on average just $15 \%$ of the variation in monthly individual prices, while most of the fluctuations in disaggregated prices reflect sector-specific shocks to which prices are adjusting quickly. Altissimo et al. (2009) document a somewhat higher portion of the common component in euro area CPI data, where it accounts for about 30 percent of the overall variance of consumer price subindices. Graeve and Walentin (2011), however, assert that the variance contribution of common shocks to sectoral inflation is a lot larger than these studies suggest. After controlling for the effects of sales and item substitutions, they found that inflation variance is driven by both aggregate and sectoral shocks.
} 
former is the $r \times 1$ vector of common factors $\left(F_{t}\right)$ that captures common sources of variation in sectoral (or provincial) inflation driven by aggregate shocks, and the latter are factor loadings that measure the 'sensitivity' of inflation in sector $i$ to the common shocks. In this model, sectoral inflation may exhibit different dynamics due either to different idiosyncratic shocks $\left(e_{i t}\right)$ or to different responses to common aggregate shocks captured by factor loadings $\left(\lambda_{i}\right)$. Before estimation, each sectoral inflation rate is demeaned to remove individual fixed effects and is further standardized by dividing by its sample standard deviation to deal with cross sectional heteroskedasticity. ${ }^{18}$ Consequently, demeaned standardized inflation rates $\left(\tilde{\pi}_{i t}=\left(\pi_{i t}-\mu_{i}\right) / \sigma_{\pi_{i t}}\right)$ are used to estimate the model based on the principal component method. The number of common factors, $r$ in eq. (2), is selected using a 'minimum rule' proposed by Greenaway-McGrevy et al. (2010) who show that the rule can get around an overestimation problem. In our case, the rule suggests one common factor $(r=1)$ for both sectoral and provincial inflation rates. ${ }^{19}$

The results from the factor analysis are reported in Table 4 . In the left panel, we estimate the factor model by using 50 sectoral inflation rates for the nation as a whole and for each province, $\pi_{i t}$ where $i=1, \ldots, 50$ denote sectors. The entry therefore represents the portion of sectoral inflation volatility that is explained by common aggregate shocks which affect all the sectors in a given province. In the right panel, the share of the common factor is estimated by using ten provincial inflation rates for a given sector, $\pi_{h t}$ where $h=1, \ldots, 10$ denote provinces. Hence it refers to the share of provincial inflation volatility that is explained by common shocks affecting all the provinces in a given sector. Table 4 illustrates several important points.

First, we confirm the growing body of evidence on disaggregated inflation that sector-specific shocks account for a dominant share of the variance in sectoral inflation. Only a small portion of the variation in sectoral inflation is explained by aggregate common shocks. At the national level, for example, merely $15.5 \%$ of the sectoral inflation volatility is explained by the common component in the full sample period. The portion of the common component gets even lower at the provincial level, varying between $7 \%(\mathrm{NFL})$ and $11 \%$ (QUB).

Second and more important, the relative importance of the common component appears to have

\footnotetext{
${ }^{18}$ The demeaning process is important in controlling for potential sources of heterogeneity across sectors. As emphasized by Huynh et al. (2011), common factor analysis could yield misleading outcomes if sector specific heterogeneity is not properly taken care of.

${ }^{19}$ The dynamics of sectoral inflation originate from both the common component and the idiosyncratic component, and here we focus on a simple common factor model for the sake of parsimony. Our approach closely follows the studies by Altissimo et al. (2009) and Reis and Watson (2010) who construct factor models based on subaggregate prices without including any other macroeconomic variables as in Boivin et al. (2009). Reis and Watson (2010) show that this factor model is able to flexibly and parsimoniously account for the main features of the economic data.
} 
declined significantly after IT adoption. The average share of the common component has fallen from a range of $10.6 \sim 22.0 \%$ in the pre-IT period to a range of $4.6 \sim 7.0 \%$ in the post-IT period. This implies that under the IT regime, the common shock plays a much smaller role in the variance of sectoral inflation. This decline in the common component share is consistent not only with our finding in Section 2 on the weaker comovements of sectoral inflation after IT adoption, but also with the heterogeneous responses between core and non-core sectors to the monetary regime change. While inflation was stabilized in many core sectors, inflation dynamics in non-core sectors were still largely dominated by external shocks from global market conditions, giving rise to lower cross-sector correlations and hence a smaller role for the common component. To gauge the connection between the timing of the decline in the common component share and the adoption of IT, we graph the dynamics of the common component share over the sample period. Figure 6 displays the estimates of the common component share for rolling windows of 12 years, with the date on the horizontal axis referring to the beginningdate of the window. ${ }^{20}$ As shown in Figure 6, the share of the common component exhibits a sudden drop in the early 1990s and remains stable thereafter, reflecting a permanent change in the common component share after the new monetary policy regime was launched by the Bank of Canada. ${ }^{21}$

Third, we notice considerable heterogeneity across sectors both in the share of the common component and its change after IT adoption. Table 5 summarizes the variance decomposition of national inflation in each sector in the pre- and post-IT periods. Comparing columns 5 and 10, it is clear that the share of the common component is highly heterogeneous even within the categories of core and non-core sectors. ${ }^{22}$ Moreover, under the IT regime, the common component share has decreased in the vast majority of core sectors while it has increased in many commodity sectors (9 of 17), suggesting that the drop in the overall common component share was principally driven by core sectors. Since the change in the common component share is ascribable to changes in either common or idiosyncratic components, it would be informative to examine how each of them has responded to the monetary

\footnotetext{
${ }^{20} 1990$ therefore captures the subsample period of 1990-2001, and so on. Similar results are obtained using rolling windows of 10 and 15 years respectively. Given the time-varying behavior of the common component, a common factor model with time-varying factor loadings suggested by Del Negro and Otrok (2008) looks more appropriate for the analysis. We do not pursue it here as our focus lies on the change between two subsamples rather than on developments over the entire sample.

${ }^{21}$ As mentioned earlier, there were other events, including the introduction of GST, that occurred in Canada around the time of IT adoption that need to be considered as potential contributors to this change in the common component. However, we do not see the introduction of GST as a compelling explanation for the observed decrease in the share of the common component. As mentioned in footnote 10, not all items were subject to GST and whether an item was subject to or exempt from GST does not correlate well with whether it exhibited a fall in the common component. Moreover, after its introduction, the GST rate was changed on only two occasions, making it an unlikely explanation for the perpetual drop in the common component share.

${ }^{22}$ Although the table only reports the case for national inflation, the results are representative of provincial inflation which we do not report to conserve the space. They are available from the authors upon request.
} 
regime change. Table 5 reports an interesting pattern between core and commodity sectors in the change of common and idiosyncratic component volatilities. While common shock volatility has increased in many commodity sectors, it has decreased in most core sectors where idiosyncratic shock volatility has actually increased, resulting in the smaller shares of common component in those core sectors. Note that the direction of total volatility change is in line with the change in the idiosyncratic shocks in the vast majority of sectors (42 of 50 sectors). Overall, our variance decomposition results indicate that the significant decline in the relative importance of common shocks after IT adoption is mainly driven by the many core sectors in which the volatility of idiosyncratic shock has increased.

Any change in the common component volatility can arise from changes either in the common factor $\left(F_{t}\right)$ that affects all sectors or in the factor loadings $\left(\lambda_{i}\right)$ that capture how sectoral inflation responds to the common shocks. The lower panel of Figure 6 plots the evolution of the estimated common factor $\left(F_{t}\right)$ which exhibits a noticeable drop in the early 1990s that coincides well with the timing of IT adoption. Although this kind of structural change in the common factor is often interpreted as being related to a new monetary policy regime [e.g. Boivin et al. (2009)], aggregate shocks more than monetary policy, such as those related to aggregate productivity, could also be responsible. Figure 7 plots the estimated common factor with the movements of major aggregate shocks, such as those relating to labor productivity, government spending, exchange rates, oil and nonfuel commodity prices, that are known to affect many, if not all, sectoral inflation rates [e.g. Reis and Watson 2010]. Interestingly, the dynamics implied by the common factor mimics remarkably well the dynamics observed in short-run interest rates, reflecting that the common factor is mainly driven by common monetary policy and its regime change. By stark contrast, other aggregate shocks appear too volatile to be compatible with the structural change observed in the common factor in the early 1990s. Therefore, it is fair to argue that the adoption of IT was most likely the driving force behind the decrease in the responsiveness of sectoral inflation to aggregate shocks, as reflected in the decline in the common component share of inflation volatility.

Turning to the other part of the common component, we notice widely different factor loadings $\left(\lambda_{i}\right)$ across sectors, indicative of the heterogeneous propagation of the common shock to sectoral inflation. Moreover, as can be seen from the last column of Table 5, sectors' sensitivities to the common shock have evolved quite differently after IT adoption, with factor loadings decreasing in most core sectors and increasing in some commodity (non-core) sectors, such as FUEL OIL (\#24) and GASOLINE (\#34). Another result, not reported here for brevity, shows that the change in common shock volatility is positively associated with the change in factor loadings, implying that sectors in 
which the sensitivity to the common factor has increased after IT adoption tend to have an increase in the portion of the common shock.

To sum, our results in the current section strongly suggest that the volatility of sectoral inflation due to common shocks has declined significantly after IT adoption, mainly driven by core sectors in which the share of common fluctuations has decreased under the new monetary regime. Since the changes in factor loadings are rather mixed across sectors, however, it is the decline in common factor that reduced the relative importance of common shock. Given that the common factor represents aggregate shocks including monetary policy, and the dynamics implied by the common factor mimics very closely the dynamics of short-run interest rates, we share the view of Boivin et al. (2009) that monetary policy regime change is likely responsible for the volatility change in sectoral inflation.

We also quantify the extent to which observed inflation variations are caused by province-wide and national factors. The right panel of Table 4 reports the share of the common component across provincial inflation rates for each sector. Although provincial inflation rates also generally fluctuate more in response to sector-specific shocks, the common component share of the provincial inflation variance looks on average larger than that of the sectoral inflation variance reported in the left panel of Table 4, indicating that inflation dynamics are much more homogeneous across provinces than across sectors. A huge variation, however, exists in the estimated common component share across sectors, ranging from 0.162 (item \#23) to 0.857 (item \#33) in the full sample. It appears that fuelrelated items (\#24 and \#34) have relatively a high common component share, mirroring a smaller dispersion of fuel-related prices across provinces. Turning to the two subsamples, a largely similar story unfolds for the heterogeneity across sectors. By comparing the two subsample periods, we note that the estimated common component has decreased after IT adoption not just in overall inflation but in the majority of sectors (30 of 50 sectors), indicating that a greater share of the variation in provincial inflation is due to the volatility of province-specific shocks after IT adoption. This implies that provincial inflation responds more slowly to common shocks that affect every province.

\section{Explanations for the heterogeneity}

A key (empirical) finding from our analysis is the heterogeneous responses of sectoral inflation to IT, with the response to the monetary policy regime change much more pronounced in the core sectors than in the commodity sectors. Even among the core sectors, a non-negligible difference exists in their responses to the change in monetary policy framework. A question then naturally arises as 
to what underlying sectoral characteristics might account for the difference in their responses to the policy regime change. Among the rich menu of potential explanations, we here consider a couple of measurable sectoral characteristics related to real and nominal frictions that have featured prominently in the literature exploring pricing behavior: (1) the degree of price stickiness; and (2) the degree of tradability. We examine whether and how these sectoral features are meaningfully correlated with the patterns of sectoral inflation observed in the preceding sections. As shown below in more detail, we find that sectors with a lower degree of price stickiness and a higher degree of tradability turn out to be more responsive to the change in the monetary policy regime.

\subsection{Price stickiness and tradability}

In recent years, the heterogeneity in price stickiness across sectors has received an enormous amount of attention from theoretical and empirical researchers alike. On the theoretical side, macroeconomic models often predict that sticky prices have important implications for both monetary policy and the dynamics of the aggregate price level [e.g. Aoki 2001] and link the largest welfare costs of inflation to the sectors with the stickiest prices [e.g. Walsh 2009], while more recent empirical studies provide concrete evidence of sectoral heterogeneity in price stickiness [e.g., Bils and Klenow 2004, Nakamura and Steinsson 2008a, Kehoe and Midrigan 2010, to name a few]. Given that sectors with more flexible price adjustment are able to respond more rapidly to changes in the economic environment, including the monetary policy framework, there are reasons to believe that the varying speed of adjustment of prices across sectors can help explain the different responses of sectoral prices to the monetary policy regime change. ${ }^{23}$ In the absence of price stickiness data for Canada, we utilize part of the extensive data set constructed by Nakamura and Steinsson (2008b) for the U.S. to evaluate whether differences in the frequency of price changes can help explain the heterogeneity we observe across sectors. ${ }^{24}$ Using

\footnotetext{
${ }^{23}$ Holding all other sectoral characteristics constant, a basic prediction of the Calvo model is that sectoral price indexes respond faster to shocks in sectors with a higher frequency of price changes [e.g. Maćkowiak et al. 2009]. Here nominal rigidities are assumed to be exogenous, although we are well aware that the degree of nominal rigidities varies across monetary policy regimes [e.g. Smets and Wouters 2007, Kimura and Kurozumi 2010]. As is often documented in the literature [e.g., Kiley 2000, Nakamura and Steinsson 2008b], the degree of price stickiness is systematically related to the inflation regime via monetary regime change. Consequently, the adoption of an inflation targeting (IT) framework per se might have exerted a significant impact on the degree of price stickiness, in that a stronger commitment to a numerical target for inflation brings about a higher degree of nominal rigidity via the sluggish response of inflation expectations. Our results, however, are arguably robust to this critique if the order of sectoral price stickiness does not change after IT adoption.

${ }^{24}$ Nakamura and Steinsson (2008b) document the frequency of price changes for non-shelter consumer prices for some 270 entry-level items for the period 1998-2005. As shown by Nakamura and Steinsson (2008b), the degree of price flexibility measured by the frequency of price change can be transformed to the degree of price stickiness using the formula for implied duration, $d=\frac{-1}{\ln (1-f)}$, where $f$ denotes the frequency of price change. Here we adhere to the price flexibility measure because the nonlinear transformation alters the one-to-one mapping.
} 
Table 17 of a supplement to their paper as a guide, where the correspondence between the entry-level items (ELI's) and major product groups are documented, we match the relevant ELI's to 45 of the 50 items in our study. We then use the data on the frequency of price changes and expenditure weights contained in Table 19 of the same supplement to calculate a measure of price stickiness for each of these 45 items based on the weighted mean of the frequency of price changes for the constituent ELI's.

The literature also often documents differences in price movements between tradable and nontradable goods, as exemplified by the Balassa-Samuelson effect. As such, it is conceivable that variation in the degree of tradability across the CPI items could generate differences in the response to the monetary policy regime change. Specifically, we would expect a faster response in sectors with higher tradability, where shocks are more rapidly transmitted across provinces partly due to more common intermediate inputs. This implies a smaller share of the common component after IT adoption in these more tradable sectors. ${ }^{25}$ By utilizing highly disaggregated U.S. NIPA data on retail and manufacturing gross output and input-output data, Crucini and Shintani (2008) measure sectoral distribution margins that capture the difference between what final consumers pay and what producers receive. Since the difference encompasses all the real costs associated with the movement of goods and services from the producer to the consumer plus markups over marginal cost, these margins can be viewed as measures of the degree of tradability of the good in question, with tradability falling as the distribution margin moves from zero (traded) to one (non-traded) (Crucini and Shintani 2008, p.632). Drawing on the approach of Crucini and Shintani (2008), we consider the variation in distribution margins across sectors as a potential explanation for the heterogeneous response to the monetary policy regime change. We match their raw data to the corresponding CPI sectors for Canada. ${ }^{26}$

In Figure 8, we plot the scatterplots of these product specific characteristics along with several measures of the sectoral inflation dynamics: (1) volatility (on the top row); (2) persistence (on the middle row); and (3) share of the common component (on the bottom row). A visual inspection of the scatterplots reveals that sectors with a higher frequency of price changes (and thus more flexible price adjustments) appear to have more volatile but less persistent sectoral inflation and a smaller portion of inflation variance explained by the common shock. The graphs on the right-hand side show that sectors which are more tradable, such as commodity sectors, tend to have more volatile but less persistent sectoral inflation, and a smaller role for the common component shock in explaining their

\footnotetext{
${ }^{25}$ Studying euro area inflation differentials, Altissimo et al. (2005) conclude that the main source of dispersion in countries' headline inflation rates is the price dispersion in the non-traded sectors such as services.

${ }^{26}$ Due to the importance of non-traded inputs and possibly higher markups in the margin, the distribution margin is also related to sectoral markup rates. We thank Moto Shintani for kindly sharing the data.
} 
variance.

\subsection{Regression analysis}

To examine further to what extent these sector specific characteristics can explain the substantial heterogeneity in the dynamics of sectoral inflation, we regress several measures of sectoral inflation dynamics on the sector-specific characteristic variables in the following pooling regression setup.

$$
Y_{i j}=\sum_{p=1}^{n} \gamma_{h} D^{p}+\beta_{1} P R I C E_{i}+\beta_{2} \operatorname{NONTRADABILITY} Y_{i}+\varepsilon_{i j}
$$

where $Y_{i j}$ denotes measures of sectoral inflation dynamics for the $i_{t h}$ sector in $j_{t h}$ province, $D^{p}$ is a province dummy variable, and 'PRICE' and 'NONTRADABILITY' respectively represent the frequency of price changes and the distribution margin in each sector under the assumption that these sector-specific characteristics are common to all provinces.

Table 6 presents the regression results in three panels. Each panel reports the results of a regression that runs a different measure of sectoral inflation dynamics, persistence (top panel), volatility (middle panel), and the common component share (bottom panel), against the two sector specific characteristics with provincial dummy variables. In each case, the results are reported for the full sample as well as the three subsamples for both core and noncore sectors. Our exercise offers somewhat encouraging results on the role of price flexibility on sectoral inflation dynamics. In the full sample with all sectors, it has the anticipated signs and is statistically significant for all measures of inflation dynamics, after holding the nontradability of sectors constant. That is, sectors with a higher frequency of price changes and thus more flexible price adjustments appear to have more volatile but less persistent sectoral inflation, and a smaller portion of inflation volatility is explained by common shocks, consistent with our prior belief. Moreover, our subsample analysis enables us to trace the impact of the monetary regime change. Under the IT regime, the role of price flexibility seems to be accentuated in the dynamics of sectoral inflation. More interestingly, price flexibility has qualitatively different impacts on core and noncore sectors. On the persistence of sectoral inflation, for example, it consistently exerts a negative impact for the noncore sectors but a positive impact for the core sectors. Its effect on the common component share, however, runs in the opposite directions as the share of the common component is positively associated with price flexibility in the noncore sectors but negatively related in the core sectors. Only in the volatility of sectoral inflation does price flexibility exert positive impacts on both core and noncore sectors and its effect is strengthened after IT adoption.

Nontradability also has a significant effect on the dynamics of sectoral inflation. As reported on the 
right-hand side of Table 6 , for all sectors, the nontradability variable takes the expected negative sign for volatility and positive signs for persistence and the common component share, and is statistically significant in most cases under study. This implies that sectors which are less tradable (with larger distribution margins) tend to have more persistent but less volatile sectoral inflation rates whose volatility is more dominated by common shocks. Its impact, however, appears to have attenuated after IT adoption, except its influence on persistence in which the coefficient estimate has substantially increased from 0.293 to 0.439 . In contrast to the role of price flexibility, nontradability imparts opposite impacts between core and noncore groups only for volatility.

To sum, our regression results suggest that both price flexibility and nontradability are significant in explaining the heterogeneous dynamics of sectoral inflation. Not only do their effects largely conform to our initial intuition, but the two sector-specific characteristics yield qualitatively corroborating results with regard to our key conclusion: sectors with more flexible prices and that are more tradable tend to have less persistent but more volatile sectoral inflation dynamics and a lower portion of its variance explained by common shocks. Having said that, the adoption of IT appears to have exerted mixed impacts on the relationship between the characteristics and the dynamics of sectoral inflation. Under the new regime, the effect of price flexibility has strengthened on all measures of inflation dynamics while the role of nontradablity has intensified only for persistence. This is believed to have resulted from disparate impacts of sector specific characteristics on core and noncore sectors. Under the IT regime, moreover, the impact of price flexibility on persistence is much more strongly associated with core sectors than with noncore sectors, while it goes the other way around for its impact on volatility and the common component share. Our results therefore supports our earlier findings that the adoption of IT has influenced inflation in different sectors in a different manner.

\section{Concluding remarks}

In this study, we have taken what we believe is a novel approach to assessing how a change in the monetary policy framework impacts the behavior of headline inflation. Using disaggregate Canadian data at both the provincial and national level for 50 sectors, we examine the impact of the adoption of IT on sectoral and provincial inflation dynamics. Our aims were to assess the subaggregate inflation responses to the adoption of IT and to identify the sectors or regions of the economy that were more sensitive to the change in the monetary framework. Not surprisingly, we find a marked difference between the behavior of the traditionally volatile commodity sectors, such as food and energy, and 
the core sectors, such as manufacturing and services. In line with much of the literature, we find that the change in the national monetary policy framework in Canada had little impact on the price dynamics for commodity items, where prices are determined largely by global factors. The influence of the policy regime change is felt predominantly in the core sectors of the economy, where national policy decisions are far more likely to influence pricing decisions.

Beyond this well-documented dichotomy between the behavior of core and commodity prices, however, we find a substantial degree of heterogeneity within the core sectors and trace its origins to industry-specific characteristics such as the degree of flexibility in sectoral prices and the degree of tradability of the goods and services in the sector. Overall, our study indicates that sectors with greater price flexibility and whose goods and services are more tradable tend to be more sensitive to the change in the monetary policy framework.

In terms of the debate surrounding the roles of core versus headline measures of inflation for policy purposes, our results provide evidence in support of a prominent role for core inflation measures [e.g. Cecchetti et al. 2009]. Currently, the inflation target in Canada is defined in terms of a headline inflation rate with core inflation used as an operational guide given its merit in predicting trend headline inflation. Of the approximately 25 inflation targeting countries, almost all use a headline measure to define their target and allow the flexibility given by a target range, a medium-term horizon and/or escape clauses to act as a buffer for fluctuations in commodity prices. ${ }^{27}$ Our results therefore suggest that a greater focus on core inflation measures seems to be a step in the right direction.

Knowledge about the sources of the heterogeneity observed within the core sectors can be used to inform policymakers when formulating their communication policy, which is a key tool for effective management of inflation expectations. Moreover, it can give policymakers a clearer view of the impact of aggregate inflation on the variability in relative prices, and consequently a better understanding of the welfare costs of inflation. For countries considering a change to their monetary policy framework, our findings suggest that their ability to predict the impact of the new regime and successfully design a transition to that regime could be enhanced by taking into account the sectoral composition of their economy. For example, if a country is thinking about specifying a numerical target for inflation and its headline inflation rate gives substantial weight to commodity-type items, it may need to consider a wider target range than normal or use a core measure for its target. This may be a particularly important issue for less-developed countries, where primary resources often constitute a larger share of the economy.

\footnotetext{
${ }^{27}$ As a major exception, Thailand utilizes directly a core measure of inflation as its target.
} 
While this study unveils several interesting findings, as with any analysis of this kind, it leaves many questions for future research. One potentially fruitful avenue to pursue focuses on further exploration of the dichotomous behavior of core and commodity sector prices. Commodities are important inputs into many non-commodity items, giving rise to some interesting questions about the pass-through from commodity to core sector prices [e.g. Clark and Terry 2010]. Another path might be to examine additional potential sources of the heterogeneity in the responsiveness across the core sectors, such as the share of imported content in the goods produced, or the breakdown between durable goods, non-durable goods and services. The current study leaves no doubt that a change in the framework governing a macroeconomic policy affects the various sectors of the economy differently, opening up many interesting related questions. 


\section{References}

[1] Altissimo, F., Benigno, P., Palenzuela, D.R., 2005, Long-run determinants of inflation differentials in a monetary union. NBER Working Papers No. 11473, National Bureau of Economic Research.

[2] Altissimo, F., Bilke, L., Levin, A., Mathä, T., Mojon, B., 2006, Sectoral and aggregate inflation dynamics in the euro area. Journal of the European Economic Association 4, 585-593.

[3] Altissimo, F., Mojon, B., Zaffaroni, P., 2009, Can aggregation explain the persistence of inflation? Journal of Monetary Economics 56, 231-241.

[4] Amano, R., Murchison, S., 2005, Factor-Market Structure, Shifting Inflation Targets, and the New Keynesian Phillips Curve. Working Paper, Bank of Canada.

[5] Ambler, S., 2009, Price-level targeting and stabilisation policy: A survey. Journal of Economic Surveys 23(5), 974-997.

[6] Anand, R., Prasad, E.S., 2010, Optimal price indices for targeting inflation under incomplete markets. NBER Working Papers No. 16290, National Bureau of Economic Research.

[7] Aoki, K., 2001, Optimal monetary policy responses to relative-price changes. Journal of Monetary Economics 48, 55-80.

[8] Bai, J., Perron, P., 1998, Estimating and testing linear models with multiple structural changes. Econometrica 66(1), 47-78.

[9] Benati, L., 2008, Investigating inflation persistence across monetary regimes. Quarterly Journal of Economics 123(3), 1005-1060.

[10] Bernanke, B.S., Boivin, J., Eliasz, P., 2005, Measuring the effects of monetary policy: A factoraugmented vector autoregressive (FAVAR) approach. Quarterly Journal of Economics 120(1), $387-422$.

[11] Bilke, L., 2005, Break in the mean and persistence of inflation - A sectoral analysis of French CPI. ECB Working Paper No. 463, European Central Bank.

[12] Bils, M., Klenow, P.J., 2004, Some evidence on the importance of sticky prices. Journal of Political Economy 112, 947-985.

[13] Boivin, J., Giannoni, M.P., Mihov, I., 2009, Sticky prices and monetary policy: Evidence from disaggregated US data. American Economic Review 99(1), 350-384.

[14] Boivin, J., Ng, S., 2006, Are more data always better for factor analysis?. Journal of Econometrics $132,169-194$.

[15] Bryan, M.F., Cecchetti, S.G., 1994, Measuring core inflation, in Monetary Policy, ed. by N. G. Mankiw, vol. 29 of National Bureau of Economic Research Studies in Business Cycles, pp.195-215. The University of Chicago Press.

[16] Carvalho, C., Nechio, F., 2011, Aggregation and the PPP Puzzle in a Sticky-Price Model, American Economic Review 101, 2391-2424.

[17] Cecchetti, S.G., Moreno, R., Mihaljek, D., Villar, A., Saxena, S.C., 2009, Monetary policy and the measurement of inflation: prices, wages and expectations, BIS Paper 49, Bank for International Settlements.

[18] Choi, C.Y., 2010, Reconsidering the relationship between inflation and relative price variability. Journal of Money, Credit and Banking 42, 769-98.

[19] Clarida, R., Gali, J., Gertler, M., 2002, A simple framework for international monetary policy analysis. Journal of Monetary Economics 49(5), 877-904. 
[20] Clark, T.E., 2001, Comparing measures of core inflation. Economic Review, Federal Reserve Bank of Kansas City, 5-31.

[21] Clark, T.E., 2006, Disaggregate evidence on the persistence of consumer price inflation. Journal of Applied Econometrics 21(5), 563-587.

[22] Clark, T.E., Terry, S.J., 2010, Time variation in the inflation passthrough of energy prices. Journal of Money, Credit and Banking 42(7), 1419-1433.

[23] Crucini, M.J., Shintani, M., 2008, Persistence in law of one price deviations: Evidence from micro-data. Journal of Monetary Economics 55, 629-644.

[24] de Resende, C., Dib, A., Kichian, M., 2010, Alternative Optimized Monetary Policy Rules in Multi-Sector Small Open Economies: The Role of Real Rigidities. Working Papers No. 2010-9, Bank of Canada.

[25] Del Negro, M., Otrok, C., 2008, Dynamic factor models with time-varying parameters: Measuring changes in international business cycles. Staff Reports No. 326, Federal Reserve Bank of New York.

[26] Erceg, C.J., Levin, A.T., 2003, Imperfect Credibility and Inflation Persistence, Journal of Monetary Economics 50(4), 915-944.

[27] Eusepi, S., Hobijn, B., Tambalotti, A., 2011, CONDI: A Cost-of-Nominal-Distortions Index. American Economic Jounral: Macroeconomics 3, 53-91.

[28] Graeve, F.D., Walentin, K., 2011, Stylized (Arte) Facts on Sectoral Inflation. Working Paper 254, Sveriges Riksbank.

[29] Greenaway-McGrevy, R., Han, C., Sul, D., 2010, The role of standardization in the estimation of common factors. Mimeo, University of Texas at Dallas.

[30] Hansen, B., 1999, The grid bootstrap and the autoregressive model. Review of Economics and Statistics 81(4), 594-607.

[31] Huang, K., Liu, Z., 2005, Inflation Targeting: What Inflation Rate to Target?, Journal of Monetary Economics 52(8), 1435-1462.

[32] Huynh, K.P., Jacho-Chavez, D.T., Petrunia, R.J., Voia, M., 2011, Functional Principal Component Analysis of Density Families with Categorical and Continuous Data on Canadian Entrant Manufacturing Firms. Journal of the American Statistical Association 106, 858-878.

[33] Kehoe, P.J., Midrigan, V., 2010, Prices are sticky after all. Staff Report 413, Research Department, Federal Reserve Bank of Minneapolis.

[34] Kimura, T., Kurozumi, T., 2010, Endogenous nominal rigidities and monetary policy. Journal of Monetary Economics 57, 1038-1048.

[35] Kiley, M.T., 2000, Price stickiness and business cycle persistence. Journal of Money, Credit, and Banking 32(1), 28-53.

[36] Kozicki, S., Tinsley, P.A., 2001, Term structure views of monetary policy under alternative models of agent expectations. Journal of Economic Dynamics and Control 25, 149-184.

[37] Kryvtsov, O., Shukayev, M., Ueberfeldt, A., 2011, Optimal monetary policy under incomplete markets and aggregate uncertainty: A long-run perspective. Journal of Economic Dynamics and Control, forthcoming.

[38] Levin, A.T., Piger, J.M., 2004, Is inflation persistence intrinsic in industrial economies?. ECB Working Paper No. 334, European Central Bank. 
[39] Longworth, D., 2002, Inflation and the Macroeconomy: Changes from the 1980s to the 1990s. Bank of Canada Review.

[40] Maćkowiak, B., Moench, E., Wiederholt, M., 2009, Sectoral price data and models of price setting. Journal of Monetary Economics 56, S78-S99.

[41] Nakamura, E., Steinsson, J., 2008a, Monetary non-neutrality in a multi-sector menu cost model. NBER Working Papers No. 14001, National Bureau of Economic Research.

[42] Nakamura, E., Steinsson, J., 2008b, Five facts about prices: A reevaluation of menu cost models. Quarterly Journal of Economics 123, 1415-64.

[43] Orphanides, A., Williams, J.C., 2005, The decline of activist stabilization policy: Natural rate misperceptions, learning, and expectations. Journal of Economic Dynamics and Control 29(11), 1927-1950.

[44] Rauch, J.E., 1999, Networks versus markets in international trade. Journal of International Economics 48, 7-35.

[45] Ravenna, F., 2006, The impact of inflation targeting: A structural analysis. Working Paper, UC Santa Cruz.

[46] Reis, R., Watson, M.W., 2010, Relative goods' prices, pure inflation, and the Phillips correlation. American Economic Journal: Macroeconomics 2, 128-157.

[47] Roberts, J.M., 2006, Monetary Policy and Inflation Dynamics. International Journal of Central Banking, September, 193-230.

[48] Smets, F., Wouters, R., 2007, Shocks and frictions in U.S. business cycles: a Bayesian DSGE approach. American Economic Review 97, 586-606.

[49] Stock, J.H., Watson, M.W., 2007, Why has U.S. inflation become harder to forecast?. Journal of Money, Credit and Banking 39(1), 3-33.

[50] Svensson, L.E.O., 2010, Inflation targeting. NBER Working Papers No. 16654, National Bureau of Economic Research.

[51] Walsh, C.E., 2009, Inflation targeting: What have we learned?. International Finance 12(2), $195-233$. 


\section{Appendix: Data Description}

Table A.1: Data Description

\begin{tabular}{|c|c|c|c|c|c|c|c|c|}
\hline \multirow[b]{2}{*}{ Item No. } & \multirow[b]{2}{*}{ Item } & \multicolumn{7}{|c|}{ Weights } \\
\hline & & 1986 & 1992 & 1996 & 2001 & 2004 & 2005 & 2007 \\
\hline 1 & Overall & 100.00 & 100.00 & 100.00 & 100.00 & 100.00 & 100.00 & 100.00 \\
\hline 2 & Fresh or frozen beef & 1.27 & 1.05 & 0.88 & 0.70 & 0.74 & 0.72 & 0.72 \\
\hline 3 & Fresh or frozen pork & 0.35 & 0.33 & 0.34 & 0.24 & 0.28 & 0.26 & 0.24 \\
\hline 4 & Fresh or frozen poultry meat & 0.53 & 0.52 & 0.67 & 0.55 & 0.62 & 0.61 & 0.63 \\
\hline 5 & Fish & 0.39 & 0.31 & 0.29 & 0.27 & 0.26 & 0.26 & 0.25 \\
\hline 6 & Fresh milk & 0.97 & 0.69 & 0.74 & 0.51 & 0.52 & 0.54 & 0.56 \\
\hline 7 & Butter & 0.16 & 0.13 & 0.12 & 0.10 & 0.10 & 0.11 & 0.11 \\
\hline 8 & Eggs & 0.20 & 0.16 & 0.18 & 0.13 & 0.13 & 0.13 & 0.14 \\
\hline 9 & Bakery and cereal products (excl. infant food) & 1.65 & 1.91 & 2.04 & 1.72 & 1.75 & 1.78 & 1.84 \\
\hline 10 & Fruit, fruit preparations and nuts & 1.29 & 1.31 & 1.40 & 1.31 & 1.31 & 1.25 & 1.27 \\
\hline 11 & Vegetables and vegetable preparations & 1.52 & 1.27 & 1.25 & 1.20 & 1.12 & 1.11 & 1.23 \\
\hline 12 & Sugar and confectionery & - & 0.34 & 0.43 & 0.40 & 0.42 & 0.42 & 0.42 \\
\hline 13 & Fats and oils & 0.18 & 0.18 & 0.19 & 0.14 & 0.14 & 0.14 & 0.14 \\
\hline 14 & Coffee and tea & 0.26 & 0.33 & 0.25 & 0.17 & 0.18 & 0.18 & 0.18 \\
\hline 15 & Non-alcoholic beverages & 0.43 & 0.59 & 0.50 & 0.69 & 0.72 & 0.75 & 0.73 \\
\hline 16 & Food purchased from restaurants & - & 5.42 & 4.98 & 5.03 & 5.17 & 5.13 & 5.15 \\
\hline 17 & Rented accommodation & 7.75 & 7.27 & 7.17 & 6.10 & 6.14 & 5.47 & 5.36 \\
\hline 18 & Replacement cost & 1.32 & 3.50 & 2.68 & 3.03 & 3.29 & 3.04 & 3.27 \\
\hline 19 & Property taxes (including special charges) & 2.83 & 3.32 & 3.55 & 3.09 & 3.15 & 3.27 & 3.31 \\
\hline 20 & Homeowners' home and mortgage insurance & 0.73 & 0.87 & 1.05 & 1.01 & 1.18 & 1.06 & 1.15 \\
\hline 21 & Homeowners' maintenance and repairs & - & 1.30 & 1.69 & 1.76 & 1.81 & 1.52 & 1.51 \\
\hline 22 & Electricity & 1.89 & 2.82 & 2.65 & 2.13 & 2.60 & 2.45 & 2.51 \\
\hline 23 & Water & 0.33 & 0.47 & 0.39 & 0.48 & 0.52 & 0.46 & 0.51 \\
\hline 24 & Fuel oil and other fuels & 0.40 & 0.54 & 0.58 & 0.43 & 0.47 & 0.41 & 0.42 \\
\hline 25 & Communications & 1.57 & 2.02 & 2.79 & 2.65 & 2.64 & 3.01 & 2.95 \\
\hline 26 & Household chemical products & 0.83 & 0.70 & 0.73 & 0.52 & 0.51 & 0.53 & 0.51 \\
\hline 27 & Paper, plastic and foil supplies & 0.87 & 0.76 & 0.79 & 0.68 & 0.67 & 0.60 & 0.59 \\
\hline 28 & Furniture and household textiles & - & 2.04 & 1.89 & 1.92 & 1.92 & 2.09 & 1.99 \\
\hline 29 & Household equipment & 1.96 & 1.78 & 1.64 & 1.63 & 1.56 & 1.78 & 1.64 \\
\hline 30 & Children's clothing (including infants) & 0.76 & 0.50 & 0.45 & 0.38 & 0.36 & 0.49 & 0.45 \\
\hline 31 & Footwear & 1.11 & 0.91 & 0.93 & 0.86 & 0.85 & 0.91 & 0.88 \\
\hline 32 & Clothing material, notions and services & - & 0.64 & - & 0.44 & 0.45 & 0.34 & 0.34 \\
\hline 33 & Purchase and leasing of passenger vehicles & - & - & 7.02 & 8.37 & 8.00 & 7.83 & 7.60 \\
\hline 34 & Gasoline & 3.09 & 3.54 & 3.93 & 3.70 & 4.48 & 4.49 & 4.92 \\
\hline 35 & Passenger vehicle insurance premiums & 2.14 & 3.09 & 3.35 & 2.70 & 2.87 & 2.94 & 2.96 \\
\hline 36 & City bus and subway transportation & 0.49 & 0.45 & 0.46 & 0.40 & 0.42 & 0.43 & 0.43 \\
\hline 37 & Medicinal and pharmaceutical products & 0.50 & 0.61 & 0.76 & 0.87 & 0.87 & 0.96 & 0.92 \\
\hline 38 & Personal care supplies and equipment & 1.62 & 1.60 & 1.55 & 1.31 & 1.31 & 1.34 & 1.27 \\
\hline 39 & Personal care services & 0.98 & 0.96 & 0.95 & 0.96 & 0.99 & 1.01 & 0.99 \\
\hline 40 & Recreational equipment and services (excl. vehicles) & 1.71 & 1.79 & 2.06 & 2.12 & 1.90 & 2.24 & 1.76 \\
\hline 41 & Purchase and operation of recreational vehicles & 0.91 & 1.16 & 1.07 & 1.31 & 1.38 & 1.46 & 1.43 \\
\hline 42 & Home entertainment equipment, parts and services & 1.39 & 1.39 & 1.56 & 1.32 & 1.25 & 1.38 & 1.19 \\
\hline 43 & Traveller accommodation & 0.97 & 1.05 & 0.99 & 0.78 & 0.82 & 1.20 & 1.15 \\
\hline 44 & Cablevision and satellite services (incl. pay TV) & 0.49 & 0.66 & 0.74 & 0.99 & 1.04 & 1.04 & 1.08 \\
\hline 45 & Education & 1.30 & 1.56 & 1.92 & 2.30 & 2.43 & 2.67 & 2.67 \\
\hline 46 & $\begin{array}{l}\text { Reading material and other printed material } \\
\text { (excl. textbooks) }\end{array}$ & - & 0.76 & 0.75 & 0.65 & 0.67 & 0.61 & 0.60 \\
\hline 47 & Alcoholic beverages served in licensed establishments & 1.40 & 0.96 & 0.58 & 0.61 & 0.63 & 0.56 & 0.55 \\
\hline 48 & Beer purchased from stores & 1.04 & 1.00 & 0.65 & 0.56 & 0.59 & 0.57 & 0.56 \\
\hline 49 & Wine purchased from stores & 0.58 & 0.47 & 0.32 & 0.26 & 0.26 & 0.29 & 0.28 \\
\hline 50 & Liquor purchased from stores & 0.79 & 0.53 & 0.33 & 0.28 & 0.28 & 0.27 & 0.27 \\
\hline 51 & Tobacco products and smokers' supplies & 2.10 & 1.55 & 1.66 & 2.10 & 2.37 & 1.33 & 1.35 \\
\hline
\end{tabular}
sectors.

Note: Bold-faced items represent the food and energy related items that are referred to throughout the paper as the 'commodity' 
Table 1: Summary Statistics of National Inflation in Canada

\begin{tabular}{|c|c|c|c|c|c|c|c|c|c|c|c|c|}
\hline & \multicolumn{3}{|c|}{ Full sample } & \multicolumn{3}{|c|}{ 1978:M9-1983:M8 } & \multicolumn{3}{|c|}{ 1983:M9-1991:M2 } & \multicolumn{3}{|c|}{ 1991:M3-2010:M5 } \\
\hline & mean & {$[10 \%, 90 \%]$} & s.d. & mean & {$[10 \%, 90 \%]$} & s.d. & mean & {$[10 \%, 90 \%]$} & s.d. & mean & {$[10 \%, 90 \%]$} & s.d. \\
\hline 1 & 3.6 & $-1.2,9.0]$ & 4.3 & 9.4 & $3.0,14.8]$ & 4.1 & 4.5 & {$[1.8,6.6]$} & 3.2 & 1.8 & {$[-2.1,5.5]$} & 3.3 \\
\hline 2 & 3.4 & {$[-17.4,27.3]$} & 21.0 & 7.2 & {$[-38.3,49.9]$} & 36.1 & 4.1 & {$[-17.5,29.5]$} & 19.5 & 2.3 & {$[-14.4,17.8]$} & 15.9 \\
\hline 3 & 2.7 & {$[-29.1,32.4]$} & 28.7 & 6.5 & {$[-54.3,71.3]$} & 44.9 & 5.4 & {$[-26.7,36.8]$} & 26.0 & 1.0 & {$[-24.0,29.2]$} & 24.0 \\
\hline 4 & 3.7 & {$[-20.3,29.9]$} & 23.7 & 7.5 & {$[-26.3,32.3]$} & 25.7 & 4.8 & {$[-32.1,37.6]$} & 34.6 & 2.3 & {$[-19.3,21.6]$} & 17.0 \\
\hline 5 & 3.8 & $-6.2,13.5]$ & 8.8 & 10.3 & $-2.1,22.5]$ & 9.5 & 4.8 & $-4.5,13.8]$ & 8.8 & 1.8 & $-7.1,11.1]$ & 7.6 \\
\hline 6 & 3.6 & $-4.2,12.0]$ & 10.2 & 9.5 & $-7.6,25.2]$ & 14.0 & 3.6 & $-6.6,11.8]$ & 9.4 & 2.0 & {$[-3.5,7.0]$} & 8.7 \\
\hline 7 & 3.8 & $-6.7,14.2]$ & 9.1 & 11.0 & $-3.8,21.6]$ & 10.1 & 2.7 & $-6.9,12.5]$ & 8.2 & 2.3 & {$[-7.6,11.4]$} & 8.3 \\
\hline 8 & 3.2 & {$[-10.9,17.8]$} & 12.1 & 6.8 & $-9.3,21.1]$ & 13.0 & 2.0 & {$[-17.0,17.8]$} & 13.7 & 2.6 & $-9.2,15.2]$ & 10.9 \\
\hline 9 & 4.3 & $-5.0,14.8]$ & 9.1 & 11.6 & $-4.0,22.0]$ & 14.4 & 3.7 & $-3.8,13.1$ & 6.6 & 2.7 & {$[-5.5,9.7]$} & 7.3 \\
\hline 10 & 3.1 & {$[-19.4,29.3]$} & 20.0 & 9.0 & {$[-22.1,32.1]$} & 21.5 & 5.4 & {$[-22.3,30.9]$} & 23.0 & 0.7 & {$[-19.2,23.9]$} & 18.0 \\
\hline 11 & 4.2 & {$[-53.8,64.7]$} & 50.7 & 10.4 & {$[-82.4,87.5]$} & 57.0 & 3.5 & {$[-64.1,68.8]$} & 58.8 & 2.7 & {$[-44.9,58.4]$} & 45.4 \\
\hline 12 & 4.1 & {$[-19.8,28.0]$} & 26.9 & 12.0 & {$[-57.4,60.3]$} & 55.6 & 2.5 & {$[-21.5,24.6]$} & 19.8 & 2.8 & {$[-15.9,20.6]$} & 16.0 \\
\hline 13 & 3.2 & {$[-7.9,14.2]$} & 10.0 & 3.9 & {$[-7.7,13.5]$} & 8.2 & 3.6 & {$[-10.4,17.8]$} & 13.6 & 2.9 & $-7.6,12.6]$ & 8.7 \\
\hline 14 & 1.4 & {$[-12.4,14.2]$} & 16.5 & 0.5 & {$[-11.2,8.1]$} & 10.6 & 0.8 & {$[-12.2,14.9]$} & 15.3 & 1.8 & {$[-14.0,14.1]$} & 18.1 \\
\hline 15 & 2.7 & {$[-25.3,32.1]$} & 25.9 & 8.8 & {$[-23.9,42.3]$} & 31.0 & 3.2 & {$[-32.6,31.6]$} & 29.5 & 0.7 & {$[-24.2,26.1]$} & 22.6 \\
\hline 16 & 4.0 & {$[0.0,8.0]$} & 5.3 & 8.8 & {$[2.3,13.3]$} & 5.0 & 5.4 & {$[1.9,7.6]$} & 8.3 & 2.3 & $0.0,4.5$ & 2.1 \\
\hline 17 & 2.9 & $1.1,6.1]$ & 2.4 & 6.5 & $2.6,9.3]$ & 2.7 & 4.1 & $1.9,6.0]$ & 1.5 & 1.5 & $0.0,2.7]$ & 0.9 \\
\hline 18 & 3.6 & {$[-2.6,9.7]$} & 6.0 & 4.8 & {$[-5.2,13.1]$} & 7.7 & 5.3 & {$[-5.6,14.2]$} & 7.9 & 2.7 & $-1.7,7.1]$ & 3.9 \\
\hline 19 & 4.2 & {$[1.2,7.1]$} & 7.1 & 6.8 & {$[0.0,8.6]$} & 13.7 & 6.2 & {$[2.5,7.4]$} & 4.5 & 2.8 & $0.0,5.5]$ & 5.0 \\
\hline 20 & 5.4 & {$[-3.0,14.3]$} & 9.4 & 8.4 & {$[-5.3,20.8]$} & 11.3 & 5.4 & $-5.0,15.5$ & 9.2 & 4.3 & $-1.6,11.1]$ & 7.2 \\
\hline 21 & 3.4 & {$[-10.4,15.1]$} & 12.9 & 9.1 & $-2.1,20.6]$ & 9.6 & 3.4 & $-8.7,13.0]$ & 12.8 & 2.0 & {$[-13.1,14.4]$} & 13.4 \\
\hline 22 & 4.3 & $-5.2,12.2]$ & 22.2 & 9.0 & $2.5,13.2]$ & 5.5 & 5.6 & {$[1.7,7.4]$} & 11.1 & 2.6 & {$[-9.2,13.9]$} & 27.3 \\
\hline 23 & 5.8 & {$[1.2,11.1]$} & 6.8 & 9.4 & $0.0,19.7]$ & 10.1 & 6.1 & {$[0.0,11.1]$} & 7.9 & 4.8 & {$[1.3,9.0]$} & 4.8 \\
\hline 24 & 6.7 & {$[-33.3,48.1]$} & 43.8 & 19.9 & $0.0,50.3]$ & 31.4 & 3.8 & {$[-23.6,29.7]$} & 33.8 & 5.0 & {$[-41.7,54.4]$} & 48.9 \\
\hline 25 & 2.1 & {$[-4.2,7.2]$} & 11.4 & 7.9 & $-5.7,15.1]$ & 20.2 & -0.2 & {$[-11.3,5.8]$} & 9.9 & 1.5 & $-4.0,4.8]$ & 8.1 \\
\hline 26 & 2.9 & $-6.3,12.8]$ & 8.7 & 11.6 & $0.0,21.3]$ & 10.7 & 3.1 & $-5.2,10.3]$ & 8.2 & 0.6 & $-7.4,7.7]$ & 6.7 \\
\hline 27 & 3.6 & $-5.5,13.3]$ & 8.4 & 10.7 & $0.0,19.5]$ & 8.0 & 3.3 & $-7.2,13.0]$ & 8.5 & 1.9 & $-6.0,9.5]$ & 7.5 \\
\hline 28 & 2.2 & $-7.2,12.6]$ & 9.5 & 7.2 & $-5.4,17.2]$ & 8.8 & 3.7 & $-6.5,13.1]$ & 8.8 & 0.3 & $-8.5,9.7]$ & 9.3 \\
\hline 29 & 1.3 & {$[-6.1,9.3]$} & 6.2 & 7.5 & $0.0,13.6]$ & 5.4 & 2.4 & {$[-2.9,8.6]$} & 5.0 & -0.7 & $-7.2,5.9]$ & 5.6 \\
\hline 30 & 1.6 & {$[-15.2,16.8]$} & 14.8 & 7.2 & $1.7,14.9]$ & 5.3 & 3.8 & $-5.6,11.1]$ & 9.8 & -0.7 & {$[-23.8,20.1]$} & 17.4 \\
\hline 31 & 2.3 & {$[-9.7,15.1]$} & 10.5 & 8.5 & {$[-1.9,17.3]$} & 8.0 & 4.0 & $-3.4,12.1]$ & 9.9 & 0.0 & {$[-13.5,14.2]$} & 10.5 \\
\hline 32 & 3.8 & {$[-1.4,9.2]$} & 5.3 & 8.5 & $2.2,13.1]$ & 5.2 & 4.9 & $0.0,8.0]$ & 6.8 & 2.1 & {$[-2.4,5.8]$} & 3.5 \\
\hline 33 & 2.7 & {$[-8.4,13.3]$} & 10.5 & 8.5 & $-2.2,20.7$ & 8.7 & 3.5 & $-5.2,13.0$ & 10.5 & 1.0 & $-9.8,10.1]$ & 10.5 \\
\hline 34 & 5.8 & {$[-41.1,52.4]$} & 44.6 & 18.6 & {$[-27.2,54.7]$} & 45.5 & 2.8 & {$[-29.6,32.1]$} & 30.3 & 3.8 & {$[-47.3,64.9]$} & 48.5 \\
\hline 35 & 6.3 & $-4.1,16.7]$ & 14.3 & 12.3 & $-5.4,27.2]$ & 22.2 & 5.7 & $-4.1,17.2]$ & 10.8 & 5.0 & $-4.1,12.5]$ & 12.6 \\
\hline 36 & 5.7 & {$[0.0,12.0]$} & 12.7 & 10.1 & {$[-14.5,26.6]$} & 25.2 & 6.8 & $2.9,11.5]$ & 5.4 & 4.3 & {$[0.0,6.8]$} & 9.6 \\
\hline 37 & 4.2 & $-2.4,11.4]$ & 6.3 & 11.6 & $5.0,17.2]$ & 6.1 & 7.2 & $2.0,10.9]$ & 5.9 & 1.2 & $-3.5,5.7]$ & 4.0 \\
\hline 38 & 2.4 & $-7.3,11.7]$ & 7.9 & 9.1 & $3.3,14.4]$ & 4.5 & 3.2 & {$[-5.5,9.9]$} & 8.5 & 0.5 & $-8.4,9.6]$ & 7.4 \\
\hline 39 & 4.0 & $0.0,8.1]$ & 6.2 & 8.4 & $2.7,15.8]$ & 6.6 & 5.8 & {$[1.9,7.5]$} & 9.0 & 2.2 & $-1.1,5.1]$ & 3.5 \\
\hline 40 & -0.8 & {$[-9.2,6.3]$} & 7.7 & 6.9 & $0.0,13.8]$ & 7.9 & 3.0 & {$[-2.6,6.3]$} & 5.1 & -4.2 & {$[-11.1,1.8]$} & 6.4 \\
\hline 41 & 4.1 & {$[-4.5,11.1]$} & 8.2 & 10.1 & $-5.7,17.7]$ & 13.1 & 5.2 & $0.0,10.8]$ & 5.5 & 2.1 & $-5.5,7.9]$ & 6.5 \\
\hline 42 & -0.7 & {$[-6.5,4.4]$} & 5.8 & 3.3 & $-1.1,7.5]$ & 3.5 & 0.7 & {$[-7.6,4.6]$} & 6.7 & -2.2 & $-7.8,2.4]$ & 5.3 \\
\hline 43 & 3.1 & {$[-19.7,21.5]$} & 24.6 & 12.2 & $0.0,21.3]$ & 11.0 & 4.8 & {$[-12.8,18.0]$} & 20.8 & 0.2 & {$[-26.3,22.4]$} & 27.8 \\
\hline 44 & 5.4 & {$[-3.5,13.8]$} & 15.5 & 7.6 & $-3.6,9.1]$ & 20.7 & 5.7 & {$[0.0,13.8]$} & 11.8 & 4.7 & {$[-3.8,13.8]$} & 15.3 \\
\hline 45 & 6.1 & {$[2.7,10.3]$} & 9.8 & 8.8 & $0.0,17.5]$ & 19.7 & 6.6 & {$[3.0,9.4]$} & 8.3 & 5.2 & {$[2.4,8.5]$} & 5.8 \\
\hline 46 & 4.9 & {$[-1.6,11.9]$} & 8.8 & 10.8 & $0.0,21.9]$ & 9.7 & 7.0 & {$[0.0,11.5]$} & 11.2 & 2.5 & {$[-3.1,8.6]$} & 6.3 \\
\hline 47 & 4.6 & {$[0.0,10.3]$} & 6.7 & 10.7 & $2.5,16.1]$ & 6.4 & 7.1 & {$[1.7,9.8]$} & 10.0 & 2.1 & $0.0,4.3]$ & 2.6 \\
\hline 48 & 5.0 & $-4.4,15.7]$ & 10.5 & 12.9 & $-5.0,28.0]$ & 16.7 & 6.6 & $-2.2,17.3]$ & 9.1 & 2.4 & $-5.4,11.2]$ & 7.5 \\
\hline 49 & 4.1 & $-3.7,12.6]$ & 10.9 & 12.3 & {$[-13.8,21.8]$} & 20.7 & 5.7 & $-4.4,14.2]$ & 9.2 & 1.3 & $-3.7,7.1]$ & 5.5 \\
\hline 50 & 3.4 & {$[-2.4,9.5]$} & 6.9 & 9.4 & {$[0.0,20.0]$} & 9.3 & 5.4 & {$[0.0,10.0]$} & 8.3 & 1.2 & {$[-2.5,5.5]$} & 3.9 \\
\hline 51 & 7.8 & {$[-4.7,22.2]$} & 31.6 & 11.4 & {$[-4.8,26.4]$} & 12.8 & 13.0 & {$[-2.7,27.3]$} & 24.4 & 3.8 & $-6.5,15.6$ & 33.3 \\
\hline
\end{tabular}

Note: Entries are the annualized monthly inflation rates. [10\%,90\%] represent the 10 -percentile and 90 -percentile values of sectoral inflation during each sample period. 
Table 2: Results of the Bai-Perron Structural Break Test

\begin{tabular}{|c|c|c|c|c|c|c|c|c|c|c|c|}
\hline Item & NAT & 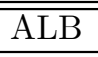 & 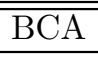 & MAN & NBW & $\begin{array}{l}\text { NFL } \\
\end{array}$ & $\begin{array}{l}\mathrm{NSC} \\
\end{array}$ & $\begin{array}{l}\text { ONT } \\
\end{array}$ & 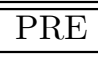 & 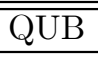 & 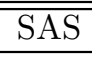 \\
\hline \multirow[t]{2}{*}{1} & $83: 07$ & $83: 05$ & 83:06 & $83: 05$ & $83: 08$ & 83:07 & $83: 05$ & $83: 05$ & $83: 05$ & $83: 07$ & $83: 06$ \\
\hline & $90: 12$ & - & $91: 10$ & $90: 12$ & $90: 12$ & 91:04 & $90: 12$ & $90: 12$ & 91:02 & 91:05 & 91:03 \\
\hline 2 & - & - & - & - & - & - & - & - & - & - & - \\
\hline 3 & - & - & - & - & - & - & - & - & - & - & - \\
\hline 4 & - & - & - & - & - & - & - & - & - & - & - \\
\hline 5 & 88:09 & 88:09 & 88:09 & - & $83: 05$ & - & - & $88: 10$ & $83: 05$ & 88:09 & - \\
\hline \multirow[t]{2}{*}{6} & $84: 12$ & 83:05 & 83:05 & - & $85: 03$ & - & $85: 05$ & - & - & - & 83:06 \\
\hline & - & 04:12 & - & - & - & - & - & - & - & - & - \\
\hline 7 & 84:04 & - & - & - & 84:03 & $83: 07$ & 83:05 & $84: 05$ & - & 84:04 & - \\
\hline 8 & - & - & - & - & - & - & - & - & - & - & - \\
\hline 9 & 83:09 & 84:03 & $83: 05$ & $83: 11$ & $83: 06$ & - & 83:06 & 84:02 & $83: 06$ & $83: 10$ & - \\
\hline 10 & - & - & - & - & - & - & - & - & - & - & - \\
\hline 11 & - & - & - & - & - & - & - & - & - & - & - \\
\hline 12 & - & - & - & - & - & - & - & - & - & - & - \\
\hline 13 & - & - & - & - & - & - & - & - & - & - & - \\
\hline 14 & - & - & - & - & - & - & - & - & - & - & - \\
\hline 15 & - & 89:08 & - & - & - & - & - & - & - & - & - \\
\hline \multirow[t]{3}{*}{16} & $83: 05$ & 83:05 & 83:06 & $83: 07$ & 91:01 & 83:09 & 83:05 & $90: 12$ & $90: 12$ & 90:12 & 91:03 \\
\hline & $90: 12$ & - & - & - & - & - & 90:12 & $00: 10$ & - & - & - \\
\hline & 99:08 & - & - & - & - & - & - & - & - & - & - \\
\hline \multirow[t]{4}{*}{17} & 84:01 & 83:05 & 84:01 & $85: 04$ & $86: 05$ & 84:05 & 86:04 & 91:01 & 84:09 & 84:02 & $84: 05$ \\
\hline & 91:04 & 88:02 & 91:08 & $92: 12$ & 92:04 & 91:03 & 92:01 & $02: 10$ & 91:07 & 89:07 & - \\
\hline & 96:01 & 92:11 & 96:06 & 00:10 & - & - & - & - & - & 94:04 & - \\
\hline & - & - & 05:07 & - & - & - & - & - & - & 00:10 & - \\
\hline \multirow[t]{3}{*}{18} & 90:01 & - & - & 03:08 & $91: 11$ & - & - & 90:01 & $89: 02$ & $88: 05$ & - \\
\hline & - & - & - & - & - & - & - & - & - & 93:04 & - \\
\hline & $99: 07$ & - & - & - & 01:02 & - & - & $96: 10$ & - & $98: 12$ & - \\
\hline \multirow[t]{2}{*}{19} & 93:03 & - & - & $98: 12$ & - & - & 83:08 & 93:04 & - & 93:03 & $86: 09$ \\
\hline & 03:03 & - & - & - & - & - & - & 01:05 & - & - & - \\
\hline \multirow[t]{2}{*}{20} & 90:01 & - & - & - & - & - & - & $89: 11$ & - & - & - \\
\hline & $00: 12$ & - & - & - & - & - & - & 99:07 & - & - & - \\
\hline 21 & $83: 05$ & - & - & - & - & - & - & - & - & - & - \\
\hline \multirow[t]{2}{*}{22} & - & - & - & - & - & - & - & - & - & 83:05 & - \\
\hline & - & - & - & - & - & - & - & - & - & 91:10 & - \\
\hline \multirow[t]{3}{*}{23} & $83: 05$ & 84:02 & - & - & - & - & - & 92:02 & - & - & - \\
\hline & - & 95:06 & - & - & - & - & - & 03:12 & - & - & - \\
\hline & - & 02:12 & - & - & - & - & - & - & - & - & - \\
\hline 24 & - & - & - & - & - & - & - & - & - & - & - \\
\hline 25 & $83: 10$ & - & - & - & - & - & - & $83: 08$ & - & - & - \\
\hline \multirow{2}{*}{26} & $83: 08$ & $83: 10$ & 83:07 & - & $83: 07$ & 83:07 & 83:05 & $83: 07$ & - & $83: 10$ & 83:08 \\
\hline & $90: 12$ & - & - & - & - & - & - & 91:07 & - & - & - \\
\hline 27 & $83: 07$ & 83:05 & 83:06 & - & $83: 05$ & 83:06 & - & 83:07 & - & 83:09 & $83: 05$ \\
\hline \multirow[t]{2}{*}{28} & $83: 12$ & - & - & - & 84:01 & - & - & $89: 12$ & - & - & $85: 03$ \\
\hline & 91:08 & - & - & - & - & - & - & - & - & - & - \\
\hline \multirow[t]{2}{*}{29} & 83:09 & 83:05 & 83:06 & 83:09 & $83: 07$ & 83:08 & $83: 10$ & 83:08 & 83:06 & 83:09 & $83: 05$ \\
\hline & $90: 12$ & 91:08 & 96:02 & - & - & - & - & - & - & - & $89: 11$ \\
\hline 30 & 91:06 & - & - & - & - & - & - & - & - & - & - \\
\hline \multirow[t]{2}{*}{31} & 83:06 & 91:07 & - & - & - & - & - & 83:06 & - & - & - \\
\hline & 91:05 & - & - & - & - & - & - & 91:02 & - & - & - \\
\hline
\end{tabular}


Table 2: Cont'd

\begin{tabular}{|c|c|c|c|c|c|c|c|c|c|c|c|}
\hline Item & $\overline{\mathrm{NAT}}$ & $\overline{\mathrm{ALB}}$ & $\overline{\mathrm{BCA}}$ & MAN & NBW & 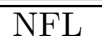 & NSC & 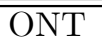 & 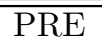 & $\overline{\text { QUB }}$ & $\overline{\mathrm{SAS}}$ \\
\hline \multirow[t]{2}{*}{32} & $83: 05$ & $83: 05$ & $83: 06$ & - & $83: 06$ & - & - & $91: 01$ & $83: 05$ & $83: 05$ & $83: 07$ \\
\hline & 91:08 & - & - & - & - & - & - & - & - & - & - \\
\hline \multirow[t]{2}{*}{33} & $86: 04$ & $96: 11$ & $96: 11$ & $97: 05$ & $86: 04$ & $96: 11$ & $96: 11$ & $86: 04$ & $86: 09$ & $86: 11$ & $96: 11$ \\
\hline & $97: 05$ & - & - & - & $97: 02$ & - & - & $97: 05$ & - & - & - \\
\hline 34 & - & - & - & - & - & - & - & - & - & - & - \\
\hline 35 & - & - & - & - & - & - & - & - & - & - & - \\
\hline 36 & $92: 02$ & $83: 12$ & - & - & - & - & - & - & - & - & - \\
\hline \multirow[t]{2}{*}{37} & $83: 06$ & $90: 12$ & $83: 06$ & $90: 12$ & $83: 06$ & $83: 08$ & $83: 06$ & $83: 06$ & 91:03 & $90: 12$ & - \\
\hline & $90: 12$ & - & $93: 06$ & - & $90: 12$ & 91:08 & $90: 12$ & 91:07 & - & - & - \\
\hline \multirow{2}{*}{38} & $83: 06$ & 83:08 & $84: 04$ & $83: 07$ & 83:09 & $83: 06$ & 84:01 & $83: 06$ & - & $83: 06$ & 83:09 \\
\hline & $90: 12$ & - & - & - & - & - & - & - & - & $90: 12$ & - \\
\hline 39 & 91:10 & $83: 05$ & $83: 05$ & - & 91:01 & - & $90: 12$ & 91:10 & - & 92:06 & $84: 03$ \\
\hline \multirow[t]{3}{*}{40} & $83: 06$ & $83: 05$ & $83: 06$ & $83: 06$ & $83: 05$ & $83: 05$ & $83: 06$ & $83: 05$ & $83: 05$ & $83: 07$ & $83: 06$ \\
\hline & $90: 12$ & 91:07 & 91:01 & $96: 04$ & $96: 11$ & $90: 12$ & $97: 01$ & 94:08 & $96: 12$ & $90: 12$ & $97: 02$ \\
\hline & $96: 11$ & 97:01 & $97: 03$ & - & - & - & - & - & - & 98:01 & - \\
\hline \multirow[t]{2}{*}{41} & $83: 07$ & $87: 09$ & $90: 12$ & $83: 06$ & $83: 07$ & $83: 07$ & $83: 07$ & $83: 05$ & $83: 07$ & $87: 03$ & 88:03 \\
\hline & $99: 12$ & - & - & $90: 12$ & 88:08 & - & $90: 12$ & 90:01 & - & - & - \\
\hline \multirow[t]{3}{*}{42} & $83: 10$ & 91:01 & 03:04 & 02:12 & $90: 12$ & - & - & 83:09 & $83: 05$ & $83: 10$ & $90: 12$ \\
\hline & 03:01 & - & - & - & - & - & - & 03:09 & - & 91:01 & - \\
\hline & - & - & - & - & - & - & - & - & - & 03:07 & - \\
\hline \multirow[t]{2}{*}{43} & $86: 04$ & - & - & - & - & - & - & $83: 06$ & - & - & - \\
\hline & 00:12 & - & - & - & - & - & - & 01:03 & - & - & - \\
\hline 44 & - & - & - & - & - & - & - & 00:07 & - & - & - \\
\hline \multirow[t]{2}{*}{45} & 98:01 & 98:01 & - & $92: 08$ & 83:08 & 98:01 & 05:01 & - & 93:08 & - & 04:01 \\
\hline & - & - & - & 99:08 & - & - & - & - & - & - & - \\
\hline \multirow[t]{2}{*}{46} & $90: 12$ & $90: 12$ & $90: 12$ & 93:04 & 91:02 & - & $83: 06$ & $90: 12$ & $85: 08$ & $90: 12$ & 91:03 \\
\hline & - & - & - & - & - & - & - & - & 97:02 & - & - \\
\hline \multirow[t]{3}{*}{47} & 83:09 & $90: 12$ & $90: 12$ & 88:01 & $90: 12$ & $86: 01$ & $90: 12$ & $90: 12$ & $90: 12$ & 91:01 & 83:09 \\
\hline & $90: 12$ & - & - & - & - & - & - & 00:02 & - & - & - \\
\hline & 00:03 & - & - & - & - & - & - & - & - & - & - \\
\hline 48 & $88: 12$ & $87: 03$ & $85: 04$ & 88:01 & $87: 12$ & 83:08 & $90: 12$ & $88: 12$ & $90: 12$ & $92: 05$ & - \\
\hline \multirow[t]{2}{*}{49} & 83:08 & $87: 04$ & $92: 12$ & 88:01 & 88:02 & - & 88:01 & 83:08 & 83:09 & $86: 03$ & - \\
\hline & $92: 10$ & - & - & - & - & - & - & 99:04 & - & - & - \\
\hline \multirow[t]{2}{*}{50} & 83:09 & 94:01 & $92: 03$ & $83: 08$ & 83:08 & 83:08 & $83: 08$ & 83:09 & 83:08 & $86: 03$ & 83:09 \\
\hline & $92: 03$ & - & - & - & - & $92: 03$ & $91: 12$ & 93:01 & $92: 03$ & - & - \\
\hline \multirow[t]{2}{*}{51} & - & - & 92:02 & 91:05 & 91:03 & $92: 11$ & 91:02 & - & - & - & $91: 03$ \\
\hline & - & - & - & - & - & 01:03 & - & - & - & - & - \\
\hline
\end{tabular}

Note: Entries represent the occurrence of break points in the year and month estimated by the sequential procedure estimation method of Bai and Perron $(1998,2003)$. We consider a pure structural change model, $\pi_{t}=\delta^{(j)}+\varepsilon_{t}$, where the breaks are assumed to be in the mean of inflation. Following the guidelines from Bai and Perron, the break is assumed not to occur during the initial $15 \%$ nor the final $15 \%$ of the sample period in testing for structural breaks. The number of breaks, their timing, and the constant are all estimated from a series of sequential Wald tests with a general error process, in which both conditional heteroskedasticity and autocorrelation are allowed. The maximum number of breaks is set to five and the minimum regime size is set to $5 \%$ of the sample. Robust standard errors are based on a quadratic spectral kernel HAC estimator with AR(1) prewhitening filters. An entry of "-" indicates that the series does not exhibit a statistically significant break. 
Table 3: Persistence estimates of sectoral inflation

\begin{tabular}{|c|c|c|c|c|c|c|c|c|c|}
\hline & \multicolumn{3}{|c|}{$\overline{\text { Full sample }}$} & \multicolumn{3}{|c|}{ 1978:M9-1991:M2 } & \multicolumn{3}{|c|}{ 1991:M3-2010:M5 } \\
\hline & MUB & {$[90 \%$ band] } & idiosyncratic & MUB & [90\% band] & idiosyncratic & MUB & [90\% band] & idiosyncratic \\
\hline 1 & 0.95 & {$[0.85,1.02]$} & common: 0.89 & 0.93 & {$[0.80,1.04]$} & common: 0.75 & 0.26 & {$[-0.15,0.62]$} & common: 0.26 \\
\hline 2 & 0.02 & {$[-0.37,0.39]$} & 0.02 & 0.13 & {$[-0.29,0.53]$} & 0.00 & 0.06 & {$[-0.25,0.36]$} & 0.08 \\
\hline 3 & 0.18 & {$[-0.14,0.50]$} & 0.03 & 0.08 & {$[-0.29,0.41]$} & 0.03 & 0.26 & {$[0.07,0.44]$} & -0.27 \\
\hline 4 & 0.23 & {$[0.09,0.37]$} & -0.37 & 0.25 & {$[0.03,0.47]$} & -0.38 & -0.21 & {$[-0.65,0.23]$} & -0.40 \\
\hline 5 & 0.82 & {$[0.61,0.96]$} & 0.44 & 0.52 & {$[0.30,0.72]$} & 0.34 & 0.31 & {$[0.07,0.53]$} & 0.32 \\
\hline 6 & 0.72 & {$[0.56,0.86]$} & 0.30 & 0.82 & {$[0.54,1.05]$} & 0.24 & 0.30 & {$[0.12,0.47]$} & -0.58 \\
\hline 7 & 0.78 & {$[0.60,0.91]$} & 0.33 & 0.94 & {$[0.72,1.13]$} & 0.31 & 0.35 & {$[0.18,0.52]$} & -0.13 \\
\hline 8 & 0.40 & {$[0.16,0.63]$} & 0.32 & 0.53 & {$[0.24,0.79]$} & 0.18 & 0.41 & {$[0.24,0.58]$} & -0.03 \\
\hline 9 & 0.83 & {$[0.64,0.94]$} & 0.46 & 0.70 & {$[0.53,0.84]$} & 0.33 & 0.53 & {$[0.36,0.69]$} & 0.14 \\
\hline 10 & -0.03 & {$[-0.28,0.22]$} & -0.06 & -0.13 & {$[-0.59,0.28]$} & -0.06 & 0.19 & {$[0.01,0.37]$} & -0.14 \\
\hline 11 & -0.24 & {$[-0.52,0.05]$} & -0.53 & -0.02 & {$[-0.43,0.37]$} & -0.55 & -0.46 & {$[-0.87,-0.05]$} & -0.62 \\
\hline 12 & -0.10 & {$[-0.31,0.12]$} & 0.45 & 0.13 & {$[-0.16,0.41]$} & 0.36 & 0.46 & {$[0.29,0.62]$} & 0.09 \\
\hline 13 & 0.30 & {$[0.06,0.52]$} & 0.49 & 0.50 & {$[0.28,0.71]$} & 0.28 & 0.40 & {$[0.20,0.58]$} & 0.43 \\
\hline 14 & 0.50 & {$[0.31,0.67]$} & 0.65 & 0.66 & {$[0.29,0.88]$} & 0.72 & 0.60 & {$[0.46,0.73]$} & 0.68 \\
\hline 15 & 0.34 & {$[0.20,0.47]$} & -0.37 & 0.41 & {$[0.18,0.62]$} & -0.31 & 0.27 & {$[0.10,0.44]$} & -0.45 \\
\hline 16 & 0.83 & {$[0.70,0.93]$} & 0.49 & 0.84 & {$[0.59,1.01]$} & 0.50 & 0.27 & {$[0.15,0.40]$} & -0.06 \\
\hline 17 & 0.98 & {$[0.93,1.02]$} & 0.78 & 0.93 & {$[0.81,1.04]$} & 0.82 & 0.83 & {$[0.69,0.94]$} & 0.71 \\
\hline 18 & 0.77 & {$[0.65,0.88]$} & 0.77 & 0.91 & {$[0.76,1.05]$} & 0.79 & 0.77 & {$[0.63,0.88]$} & 0.84 \\
\hline 19 & 0.82 & {$[0.68,0.92]$} & 0.42 & 0.36 & {$[-0.02,0.69]$} & -0.05 & 0.69 & {$[0.55,0.81]$} & -0.05 \\
\hline 20 & 0.70 & {$[0.53,0.86]$} & 0.51 & 0.75 & {$[0.51,0.89]$} & 0.33 & 0.84 & {$[0.59,1.04]$} & 0.43 \\
\hline 21 & 0.57 & {$[0.33,0.79]$} & -0.36 & 0.71 & {$[0.29,1.02]$} & -0.11 & 0.06 & {$[-0.13,0.25]$} & -0.30 \\
\hline 22 & 0.61 & {$[0.39,0.81]$} & -0.47 & 0.80 & {$[0.53,1.00]$} & 0.34 & -0.17 & {$[-0.53,0.16]$} & -1.85 \\
\hline 23 & 0.84 & {$[0.67,0.95]$} & 0.09 & 0.58 & {$[0.37,0.76]$} & -0.02 & 0.87 & {$[0.70,1.00]$} & 0.59 \\
\hline 24 & 0.01 & {$[-0.35,0.35]$} & 0.30 & 0.70 & {$[0.47,0.87]$} & 0.27 & -0.05 & {$[-0.34,0.22]$} & 0.37 \\
\hline 25 & 0.64 & {$[0.44,0.83]$} & 0.18 & 0.94 & {$[0.70,1.20]$} & 0.27 & 0.46 & {$[0.29,0.63]$} & -0.09 \\
\hline 26 & 0.87 & {$[0.71,0.97]$} & 0.08 & 0.94 & {$[0.72,1.16]$} & 0.43 & 0.30 & {$[0.11,0.48]$} & -0.09 \\
\hline 27 & 0.69 & {$[0.55,0.82]$} & 0.51 & 0.81 & {$[0.61,0.92]$} & 0.54 & 0.39 & {$[0.19,0.58]$} & 0.60 \\
\hline 28 & 0.82 & {$[0.58,0.99]$} & -0.74 & 0.42 & {$[0.20,0.64]$} & -0.28 & -0.48 & {$[-0.98,0.00]$} & -0.19 \\
\hline 29 & 0.92 & {$[0.79,1.03]$} & 0.05 & 0.93 & {$[0.73,1.12]$} & 0.50 & 0.70 & {$[0.28,1.00]$} & -0.08 \\
\hline 30 & 0.82 & {$[0.59,0.97]$} & -0.35 & 0.81 & {$[0.53,1.01]$} & -0.32 & 0.61 & {$[0.10,0.97]$} & -0.80 \\
\hline 31 & 0.64 & {$[0.45,0.82]$} & 0.24 & 0.88 & {$[0.66,1.07]$} & 0.48 & 0.47 & {$[-0.20,0.96]$} & -1.44 \\
\hline 32 & 0.79 & {$[0.64,0.92]$} & 0.10 & 0.82 & {$[0.56,1.05]$} & -0.37 & 0.48 & {$[-0.11,0.87]$} & -0.63 \\
\hline 33 & 0.69 & {$[0.50,0.84]$} & 0.47 & 0.92 & {$[0.67,1.21]$} & 0.37 & 0.81 & {$[0.55,1.01]$} & 0.45 \\
\hline 34 & 0.00 & {$[-0.26,0.23]$} & -0.10 & 0.42 & {$[0.20,0.64]$} & -0.09 & -0.30 & {$[-0.64,0.03]$} & -0.13 \\
\hline 35 & 0.53 & {$[0.35,0.70]$} & 0.46 & 0.68 & {$[0.36,0.87]$} & 0.45 & 0.54 & {$[0.33,0.74]$} & 0.52 \\
\hline 36 & 0.48 & {$[0.26,0.68]$} & -0.14 & 0.55 & {$[0.09,0.82]$} & -0.10 & 0.29 & {$[0.01,0.56]$} & 0.37 \\
\hline 37 & 0.96 & {$[0.88,1.03]$} & 0.44 & 0.73 & {$[0.53,0.88]$} & 0.09 & 0.38 & {$[0.11,0.63]$} & 0.07 \\
\hline 38 & 0.87 & {$[0.71,0.96]$} & 0.25 & 0.82 & {$[0.61,0.96]$} & -0.45 & 0.33 & {$[-0.06,0.67]$} & -0.22 \\
\hline 39 & 0.85 & {$[0.69,0.93]$} & 0.54 & 0.79 & {$[0.51,0.99]$} & 0.93 & 0.13 & {$[-0.22,0.46]$} & 0.00 \\
\hline 40 & 0.97 & {$[0.89,1.05]$} & 0.51 & 0.62 & {$[0.42,0.80]$} & -0.06 & 0.83 & {$[0.60,1.02]$} & 0.41 \\
\hline 41 & 0.87 & {$[0.69,0.98]$} & -0.18 & 0.70 & {$[0.51,0.86]$} & -0.53 & 0.13 & {$[-0.25,0.49]$} & 0.09 \\
\hline 42 & 0.86 & {$[0.68,0.99]$} & 0.45 & 0.78 & {$[0.50,0.97]$} & 0.34 & 0.86 & {$[0.58,1.14]$} & 0.41 \\
\hline 43 & 0.82 & {$[0.59,0.97]$} & -0.22 & 0.80 & {$[0.49,1.05]$} & -0.40 & 0.46 & {$[0.16,0.74]$} & -0.47 \\
\hline 44 & -0.08 & {$[-0.23,0.06]$} & -0.32 & 0.09 & {$[-0.15,0.34]$} & -0.15 & -0.25 & {$[-0.42,-0.07]$} & -0.51 \\
\hline 45 & 0.76 & {$[0.55,0.90]$} & -0.05 & 0.22 & {$[0.00,0.43]$} & -0.56 & 0.65 & {$[0.39,0.86]$} & 0.19 \\
\hline 46 & 0.73 & {$[0.56,0.88]$} & 0.26 & 0.79 & {$[0.53,0.97]$} & 0.00 & 0.12 & {$[-0.21,0.44]$} & 0.15 \\
\hline 47 & 0.92 & {$[0.81,1.00]$} & 0.22 & 0.70 & {$[0.41,0.85]$} & -0.15 & 0.85 & {$[0.64,1.02]$} & 0.17 \\
\hline 48 & 0.87 & {$[0.72,0.96]$} & 0.12 & 0.40 & {$[0.18,0.61]$} & -0.14 & 0.34 & {$[0.16,0.52]$} & -0.22 \\
\hline 49 & 0.82 & {$[0.62,0.93]$} & -0.05 & 0.42 & {$[0.21,0.61]$} & -0.03 & 0.47 & {$[0.18,0.72]$} & 0.15 \\
\hline 50 & 0.95 & {$[0.82,1.07]$} & 0.26 & 0.78 & {$[0.41,1.10]$} & 0.30 & 0.47 & {$[0.30,0.63]$} & -0.20 \\
\hline 51 & 0.43 & {$[0.31,0.55]$} & 0.09 & 0.04 & {$[-0.19,0.26]$} & -0.07 & 0.42 & {$[0.29,0.56]$} & 0.11 \\
\hline
\end{tabular}

Note: MUB (median unbiased) estimates are for the sum of AR coefficient in AR(p) model where the lag length (p) is selected using the BIC. Both MUB and the $90 \%$ confidence bands are estimated with Hansen's (1999) grid bootstrap. The table reports Hansen's (1999) mean unbiased estimator of the sum of autoregressive coefficients $\rho$ and the bootstrapped $90 \%$ confidence bands based on 101 grid points and 999 replications. The lag order is chosen according to the AIC. 
Table 4: Share of common (aggregate) shock before and after IT adoption

\begin{tabular}{|c|c|c|c|c|c|c|c|c|}
\hline \multicolumn{4}{|c|}{ Across Sectors } & \multicolumn{5}{|c|}{ Across Provinces } \\
\hline & Full sample & Pre-IT & Post-IT & Sector & Full sample & Pre-IT & Post-IT & change \\
\hline NAT & 0.155 & 0.220 & 0.051 & 1 & 0.629 & 0.593 & 0.505 & - \\
\hline ALB & 0.090 & 0.131 & 0.070 & 2 & 0.319 & 0.249 & 0.293 & + \\
\hline $\mathrm{BCA}$ & 0.087 & 0.133 & 0.051 & 3 & 0.300 & 0.305 & 0.252 & - \\
\hline MAN & 0.075 & 0.106 & 0.046 & 4 & 0.213 & 0.211 & 0.214 & + \\
\hline NBW & 0.087 & 0.144 & 0.056 & 5 & 0.284 & 0.324 & 0.256 & - \\
\hline NFL & 0.069 & 0.108 & 0.054 & 6 & 0.171 & 0.156 & 0.182 & + \\
\hline $\mathrm{NSC}$ & 0.084 & 0.127 & 0.057 & 7 & 0.232 & 0.203 & 0.199 & - \\
\hline ONT & 0.105 & 0.173 & 0.052 & 8 & 0.197 & 0.205 & 0.217 & + \\
\hline PRE & 0.080 & 0.130 & 0.052 & 9 & 0.320 & 0.220 & 0.279 & + \\
\hline QUB & 0.109 & 0.182 & 0.046 & 10 & 0.364 & 0.402 & 0.345 & - \\
\hline SAS & 0.077 & 0.115 & 0.055 & 11 & 0.659 & 0.682 & 0.665 & - \\
\hline & & & & 12 & 0.369 & 0.302 & 0.152 & - \\
\hline & & & & 13 & 0.213 & 0.270 & 0.208 & - \\
\hline & & & & 14 & 0.360 & 0.346 & 0.359 & + \\
\hline & & & & 15 & 0.221 & 0.196 & 0.237 & + \\
\hline & & & & 16 & 0.574 & 0.837 & 0.225 & - \\
\hline & & & & 17 & 0.518 & 0.338 & 0.218 & - \\
\hline & & & & 18 & 0.222 & 0.235 & 0.213 & - \\
\hline & & & & 19 & 0.259 & 0.253 & 0.273 & + \\
\hline & & & & 20 & 0.335 & 0.311 & 0.279 & - \\
\hline & & & & 21 & 0.327 & 0.266 & 0.331 & + \\
\hline & & & & 22 & 0.196 & 0.413 & 0.200 & - \\
\hline & & & & 23 & 0.162 & 0.179 & 0.193 & + \\
\hline & & & & 24 & 0.742 & 0.684 & 0.739 & + \\
\hline & & & & 25 & 0.383 & 0.372 & 0.409 & + \\
\hline & & & & 26 & 0.298 & 0.288 & 0.238 & - \\
\hline & & & & 27 & 0.332 & 0.327 & 0.331 & + \\
\hline & & & & 28 & 0.196 & 0.196 & 0.197 & + \\
\hline & & & & 29 & 0.305 & 0.306 & 0.232 & - \\
\hline & & & & 30 & 0.241 & 0.326 & 0.225 & - \\
\hline & & & & 31 & 0.193 & 0.281 & 0.157 & - \\
\hline & & & & 32 & 0.322 & 0.498 & 0.193 & - \\
\hline & & & & 33 & 0.857 & 0.892 & 0.875 & - \\
\hline & & & & 34 & 0.627 & 0.533 & 0.708 & + \\
\hline & & & & 35 & 0.288 & 0.213 & 0.309 & + \\
\hline & & & & 36 & 0.183 & 0.192 & 0.158 & - \\
\hline & & & & 37 & 0.354 & 0.215 & 0.304 & + \\
\hline & & & & 38 & 0.277 & 0.383 & 0.193 & - \\
\hline & & & & 39 & 0.340 & 0.599 & 0.184 & - \\
\hline & & & & 40 & 0.507 & 0.511 & 0.360 & - \\
\hline & & & & 41 & 0.515 & 0.358 & 0.490 & + \\
\hline & & & & 42 & 0.369 & 0.402 & 0.332 & - \\
\hline & & & & 43 & 0.474 & 0.639 & 0.509 & - \\
\hline & & & & 44 & 0.435 & 0.423 & 0.447 & + \\
\hline & & & & 45 & 0.430 & 0.244 & 0.283 & + \\
\hline & & & & 46 & 0.479 & 0.640 & 0.386 & - \\
\hline & & & & 47 & 0.397 & 0.641 & 0.170 & - \\
\hline & & & & 48 & 0.230 & 0.214 & 0.157 & - \\
\hline & & & & 49 & 0.374 & 0.349 & 0.140 & - \\
\hline & & & & 50 & 0.323 & 0.521 & 0.142 & - \\
\hline & & & & 51 & 0.595 & 0.619 & 0.559 & - \\
\hline & & & & Core & 0.699 & 0.620 & 0.828 & + \\
\hline
\end{tabular}

Note: Here the sample covers the Great Moderation period so that the 'Pre-IT' period spans 1983:M9-1991:M2. 
Table 5: Source of shocks across sectoral inflation before and after IT adoption

\begin{tabular}{|c|c|c|c|c|c|c|c|c|c|c|c|c|c|c|c|}
\hline \multirow{3}{*}{ sector } & \multicolumn{5}{|c|}{$\begin{array}{c}\text { Pre-IT (1983-1990) } \\
\end{array}$} & \multicolumn{5}{|c|}{ Post-IT (1991-2009) } & \multicolumn{5}{|c|}{ Change } \\
\hline & \multicolumn{4}{|c|}{ variance } & \multirow{2}{*}{$\begin{array}{r}\text { factor } \\
\text { loading }\end{array}$} & \multicolumn{4}{|c|}{ variance } & \multirow{2}{*}{$\begin{array}{r}\text { factor } \\
\text { loading }\end{array}$} & \multicolumn{4}{|c|}{ variance } & \multirow{2}{*}{$\begin{array}{c}\text { factor } \\
\text { loading }\end{array}$} \\
\hline & total & common & idio & ratio & & total & common & idio & ratio & & total & common & idio & ratio & \\
\hline 2 & 380.5 & 0.5 & 380.0 & 0.001 & 0.655 & 253.5 & 11.4 & 242.0 & 0.045 & 0.788 & - & + & - & + & + \\
\hline 3 & 676.1 & 3.2 & 672.9 & 0.005 & 0.661 & 574.8 & 33.9 & 540.9 & 0.059 & 0.571 & - & + & - & + & - \\
\hline 4 & 1194.2 & 43.6 & 1150.6 & 0.037 & 0.388 & 289.2 & 4.3 & 284.9 & 0.015 & 0.209 & - & - & - & - & - \\
\hline 5 & 76.9 & 2.5 & 74.3 & 0.033 & 0.675 & 58.0 & 14.7 & 43.3 & 0.253 & 0.543 & - & + & - & + & - \\
\hline 6 & 87.7 & 1.3 & 86.4 & 0.015 & -0.422 & 75.5 & 8.4 & 67.1 & 0.111 & -0.143 & - & + & - & + & + \\
\hline 7 & 67.0 & 0.4 & 66.6 & 0.006 & 0.528 & 68.5 & 12.5 & 56.0 & 0.182 & 0.581 & + & + & - & + & + \\
\hline 8 & 188.8 & 6.6 & 182.2 & 0.035 & 0.436 & 119.8 & 6.1 & 113.8 & 0.051 & 0.646 & - & - & - & + & + \\
\hline 9 & 43.3 & 1.4 & 41.9 & 0.032 & 0.147 & 52.7 & 14.7 & 38.0 & 0.279 & 0.474 & + & + & - & + & + \\
\hline 10 & 527.7 & 67.3 & 460.3 & 0.128 & 0.625 & 324.2 & 38.4 & 285.8 & 0.118 & 0.651 & - & - & - & - & + \\
\hline 11 & 3457.5 & 2.5 & 3455.0 & 0.001 & 0.815 & 2060.2 & 228.7 & 1831.5 & 0.111 & 0.813 & - & + & - & + & - \\
\hline 12 & 393.5 & 63.2 & 330.3 & 0.161 & 0.700 & 256.8 & 4.9 & 251.9 & 0.019 & -0.027 & - & - & - & - & - \\
\hline 13 & 184.0 & 1.6 & 182.3 & 0.009 & 0.573 & 75.4 & 9.9 & 65.6 & 0.131 & 0.487 & - & + & - & + & - \\
\hline 14 & 234.4 & 23.9 & 210.5 & 0.102 & 0.639 & 328.3 & 9.3 & 319.0 & 0.028 & 0.678 & + & - & + & - & + \\
\hline 15 & 869.4 & 180.6 & 688.9 & 0.208 & 0.300 & 510.0 & 26.8 & 483.3 & 0.053 & 0.417 & - & - & - & - & + \\
\hline 16 & 69.2 & 62.7 & 6.5 & 0.906 & 0.953 & 4.3 & 0.2 & 4.1 & 0.047 & 0.429 & - & - & - & - & - \\
\hline 17 & 2.4 & 0.0 & 2.3 & 0.000 & -0.726 & 0.8 & 0.1 & 0.7 & 0.125 & 0.229 & - & + & - & + & + \\
\hline 18 & 62.9 & 5.0 & 57.9 & 0.079 & 0.304 & 15.5 & 1.0 & 14.6 & 0.065 & 0.352 & - & - & - & - & + \\
\hline 19 & 20.3 & 1.5 & 18.8 & 0.074 & 0.683 & 24.5 & 1.2 & 23.3 & 0.049 & -0.371 & + & - & + & - & - \\
\hline 20 & 84.0 & 6.4 & 77.6 & 0.076 & 0.325 & 51.7 & 2.0 & 49.7 & 0.039 & 0.594 & - & - & - & - & + \\
\hline 21 & 164.9 & 56.3 & 108.6 & 0.341 & 0.610 & 179.7 & 14.0 & 165.7 & 0.078 & 0.654 & + & - & + & - & + \\
\hline 22 & 123.7 & 96.0 & 27.8 & 0.776 & 0.746 & 747.7 & 0.7 & 747.0 & 0.001 & -0.580 & + & - & + & - & - \\
\hline 23 & 61.7 & 5.7 & 56.0 & 0.092 & -0.393 & 23.4 & 1.1 & 22.3 & 0.047 & 0.471 & - & - & - & - & + \\
\hline 24 & 1140.7 & 504.3 & 636.4 & 0.442 & 0.920 & 2390.3 & 929.1 & 1461.2 & 0.389 & 0.853 & + & + & + & - & - \\
\hline 25 & 98.9 & 16.8 & 82.1 & 0.170 & 0.439 & 65.4 & 0.3 & 65.1 & 0.005 & -0.465 & - & - & - & - & - \\
\hline 26 & 67.9 & 34.4 & 33.6 & 0.507 & 0.594 & 44.6 & 6.2 & 38.4 & 0.139 & 0.571 & - & - & + & - & - \\
\hline 27 & 71.9 & 16.5 & 55.4 & 0.229 & 0.735 & 57.0 & 0.4 & 56.5 & 0.007 & 0.610 & - & - & + & - & - \\
\hline 28 & 77.1 & 21.5 & 55.6 & 0.279 & 0.587 & 86.4 & 9.9 & 76.5 & 0.115 & 0.655 & + & - & + & - & + \\
\hline 29 & 25.1 & 5.4 & 19.7 & 0.215 & 0.641 & 31.0 & 7.7 & 23.4 & 0.248 & 0.606 & + & + & + & + & - \\
\hline 30 & 96.1 & 62.5 & 33.7 & 0.650 & 0.644 & 303.2 & 7.4 & 295.7 & 0.024 & 0.607 & + & - & + & - & - \\
\hline 31 & 98.1 & 64.0 & 34.1 & 0.652 & 0.579 & 109.5 & 2.5 & 107.1 & 0.023 & 0.586 & + & - & + & - & + \\
\hline 32 & 46.2 & 33.3 & 12.8 & 0.721 & 0.816 & 12.5 & 1.5 & 11.1 & 0.120 & 0.392 & - & - & - & - & - \\
\hline 33 & 110.4 & 40.7 & 69.7 & 0.369 & 0.957 & 109.9 & 4.6 & 105.2 & 0.042 & 0.948 & - & - & + & - & - \\
\hline 34 & 919.3 & 402.7 & 516.5 & 0.438 & 0.706 & 2351.1 & 962.1 & 1389.0 & 0.409 & 0.821 & + & + & + & - & + \\
\hline 35 & 117.4 & 18.7 & 98.7 & 0.159 & 0.587 & 158.5 & 7.2 & 151.3 & 0.045 & 0.430 & + & - & + & - & - \\
\hline 36 & 29.7 & 6.4 & 23.3 & 0.215 & -0.030 & 91.2 & 5.0 & 86.2 & 0.055 & 0.700 & + & - & + & - & + \\
\hline 37 & 35.2 & 3.8 & 31.3 & 0.108 & -0.544 & 15.8 & 1.6 & 14.3 & 0.101 & 0.380 & - & - & - & - & + \\
\hline 38 & 71.8 & 41.7 & 30.1 & 0.581 & 0.425 & 54.2 & 3.7 & 50.4 & 0.068 & 0.391 & - & - & + & - & - \\
\hline 39 & 81.2 & 67.6 & 13.6 & 0.833 & 0.785 & 12.3 & 0.9 & 11.4 & 0.073 & 0.124 & - & - & - & - & - \\
\hline 40 & 25.9 & 14.0 & 11.9 & 0.541 & 0.843 & 40.3 & 7.2 & 33.1 & 0.179 & 0.668 & + & - & + & - & - \\
\hline 41 & 30.7 & 5.7 & 25.0 & 0.186 & 0.278 & 42.5 & 14.5 & 28.0 & 0.341 & 0.741 & + & + & + & + & + \\
\hline 42 & 45.5 & 28.0 & 17.4 & 0.615 & 0.604 & 27.8 & 2.7 & 25.1 & 0.097 & 0.590 & - & - & + & - & - \\
\hline 43 & 433.2 & 53.8 & 379.4 & 0.124 & 0.867 & 774.9 & 12.3 & 762.6 & 0.016 & 0.739 & + & - & + & - & - \\
\hline 44 & 139.7 & 69.5 & 70.1 & 0.497 & 0.874 & 234.6 & 4.7 & 229.9 & 0.020 & 0.896 & + & - & + & - & + \\
\hline 45 & 68.9 & 2.3 & 66.6 & 0.033 & -0.272 & 33.7 & 3.2 & 30.5 & 0.095 & 0.379 & - & + & - & + & + \\
\hline 46 & 124.5 & 102.3 & 22.2 & 0.822 & 0.790 & 39.6 & 0.0 & 39.5 & 0.000 & 0.711 & - & - & + & - & - \\
\hline 47 & 99.9 & 71.9 & 28.0 & 0.720 & 0.850 & 6.6 & 0.3 & 6.3 & 0.045 & 0.465 & - & - & - & - & - \\
\hline 48 & 83.2 & 13.5 & 69.7 & 0.162 & 0.254 & 56.4 & 3.8 & 52.6 & 0.067 & 0.292 & - & - & - & - & + \\
\hline 49 & 84.4 & 27.5 & 56.9 & 0.326 & 0.656 & 30.4 & 0.5 & 29.9 & 0.016 & 0.326 & - & - & - & - & - \\
\hline 50 & 68.7 & 24.9 & 43.8 & 0.362 & 0.594 & 15.4 & 2.3 & 13.0 & 0.149 & 0.127 & - & - & - & - & - \\
\hline 51 & 593.1 & 21.4 & 571.6 & 0.036 & 0.636 & 1109.4 & 29.1 & 1080.2 & 0.026 & 0.662 & + & + & + & - & + \\
\hline
\end{tabular}

Note: 'common', 'idio' and 'ratio' respectively denote common component, idiosyncratic component and the ratio of common component to the total volatility of sectoral inflation. 
Table 6: Regression Results

\begin{tabular}{|c|c|c|c|c|c|c|}
\hline & \multicolumn{3}{|c|}{ "Price flexibility $\left(\beta_{1}\right)$} & \multicolumn{3}{|c|}{ Non-tradability $\left(\beta_{2}\right)$} \\
\hline & All sectors & Non-core & Core & All sectors & Non-core & Core \\
\hline \multicolumn{7}{|c|}{ Persistence as regressand } \\
\hline \multirow[t]{2}{*}{ Full sample } & $-0.030 \ddagger$ & -0.011 & 0.006 & $0.341 \ddagger$ & -0.134 & $0.228 \ddagger$ \\
\hline & {$[0.012]$} & {$[0.022]$} & {$[0.014]$} & {$[0.087]$} & {$[0.227]$} & {$[0.074]$} \\
\hline \multirow[t]{2}{*}{ 1978-1983 } & -0.001 & $-0.067 \ddagger$ & $0.034 \ddagger$ & -0.111 & 0.028 & -0.198 \\
\hline & {$[0.012]$} & {$[0.023]$} & {$[0.014]$} & {$[0.084]$} & {$[0.183]$} & {$[0.171]$} \\
\hline \multirow[t]{2}{*}{ 1983-1990 } & $0.070 \ddagger$ & $-0.055 \dagger$ & $0.080 \ddagger$ & $0.293 \ddagger$ & 0.229 & $0.284 \dagger$ \\
\hline & {$[0.020]$} & {$[0.027]$} & {$[0.026]$} & {$[0.140]$} & {$[0.304]$} & [0.143] \\
\hline \multirow[t]{2}{*}{ 1991-2010 } & $-0.096 \ddagger$ & -0.026 & $0.166 \ddagger$ & $0.439 \ddagger$ & 0.021 & $0.289 \ddagger$ \\
\hline & {$[0.020]$} & {$[0.024]$} & {$[0.025]$} & {$[0.107]$} & {$[0.239]$} & [0.119] \\
\hline \multicolumn{7}{|c|}{ Volatility as regressand } \\
\hline \multirow[t]{2}{*}{ Full sample } & $2.285 \ddagger$ & $1.977^{*}$ & $0.893 \ddagger$ & $-13.557 \ddagger$ & $13.750^{*}$ & -0.843 \\
\hline & {$[0.420]$} & {$[0.996]$} & {$[0.365]$} & {$[2.695]$} & {$[8.246]$} & {$[2.210]$} \\
\hline \multirow[t]{2}{*}{ 1978-1983 } & $1.189 \ddagger$ & 0.275 & $0.355 \ddagger$ & $-9.741 \ddagger$ & 0.531 & $-8.352 \ddagger$ \\
\hline & {$[0.481]$} & {$[1.305]$} & {$[0.189]$} & {$[3.514]$} & {$[9.622]$} & [3.247] \\
\hline \multirow[t]{2}{*}{ 1983-1990 } & $1.954 \ddagger$ & 0.203 & $1.421 \ddagger$ & $-16.546 \ddagger$ & $12.001^{*}$ & $-4.258^{*}$ \\
\hline & {$[0.378]$} & {$[0.990]$} & {$[0.404]$} & {$[3.030]$} & [8.183] & {$[2.397]$} \\
\hline \multirow[t]{2}{*}{$1991-2010$} & $2.509 \ddagger$ & $2.760 \ddagger$ & $0.732 \dagger$ & $-14.621 \ddagger$ & $15.805^{*}$ & $-1.521 \dagger$ \\
\hline & {$[0.500]$} & [1.128] & {$[0.364]$} & [2.814] & {$[9.726]$} & {$[0.764]$} \\
\hline \multicolumn{7}{|c|}{ Common component share as regressand } \\
\hline \multirow[t]{2}{*}{ Full sample } & $-0.010 \ddagger$ & $0.013 \ddagger$ & $-0.013 \ddagger$ & $0.127 \ddagger$ & 0.071 & $0.020^{*}$ \\
\hline & {$[0.004]$} & {$[0.005]$} & {$[0.005]$} & {$[0.025]$} & {$[0.054]$} & [0.011] \\
\hline \multirow[t]{2}{*}{ 1978-1983 } & $-0.010 \ddagger$ & 0.006 & $-0.015 \ddagger$ & -0.041 & -0.034 & $-0.093 \ddagger$ \\
\hline & {$[0.004]$} & {$[0.007]$} & {$[0.004]$} & {$[0.023]$} & [0.069] & {$[0.030]$} \\
\hline \multirow[t]{2}{*}{ 1983-1990 } & 0.001 & $0.040 \ddagger$ & -0.009 & $0.350 \ddagger$ & $0.349 \ddagger$ & $0.183 \ddagger$ \\
\hline & {$[0.007]$} & {$[0.009]$} & {$[0.009]$} & {$[0.045]$} & {$[0.093]$} & {$[0.055]$} \\
\hline \multirow[t]{2}{*}{$1991-2010$} & -0.005 & $0.021 \ddagger$ & -0.003 & 0.006 & -0.073 & $0.035^{*}$ \\
\hline & {$[0.004]$} & {$[0.010]$} & {$[0.004]$} & {$[0.025]$} & {$[0.083]$} & [0.019] \\
\hline
\end{tabular}

Note: Regression equation is $Y_{i j}=\sum_{p=1}^{n} \gamma_{h} D^{p}+\beta_{1} P R I C E_{i}+\beta_{2} N O N T R A D A B I L I T Y_{i}+\varepsilon_{i j}$, where $Y_{i j}$ denotes measures of sectoral inflation dynamics for $i_{t h}$ sector in $j_{t h}$ province and $D^{p}$ is a province dummy variable. The numbers in square brackets report the standard errors after correcting for heteroskedasticity. * $*^{\dagger}$ and $\ddagger$ indicate statistical significance at the $1 \%, 5 \%$ and $10 \%$ error levels. 

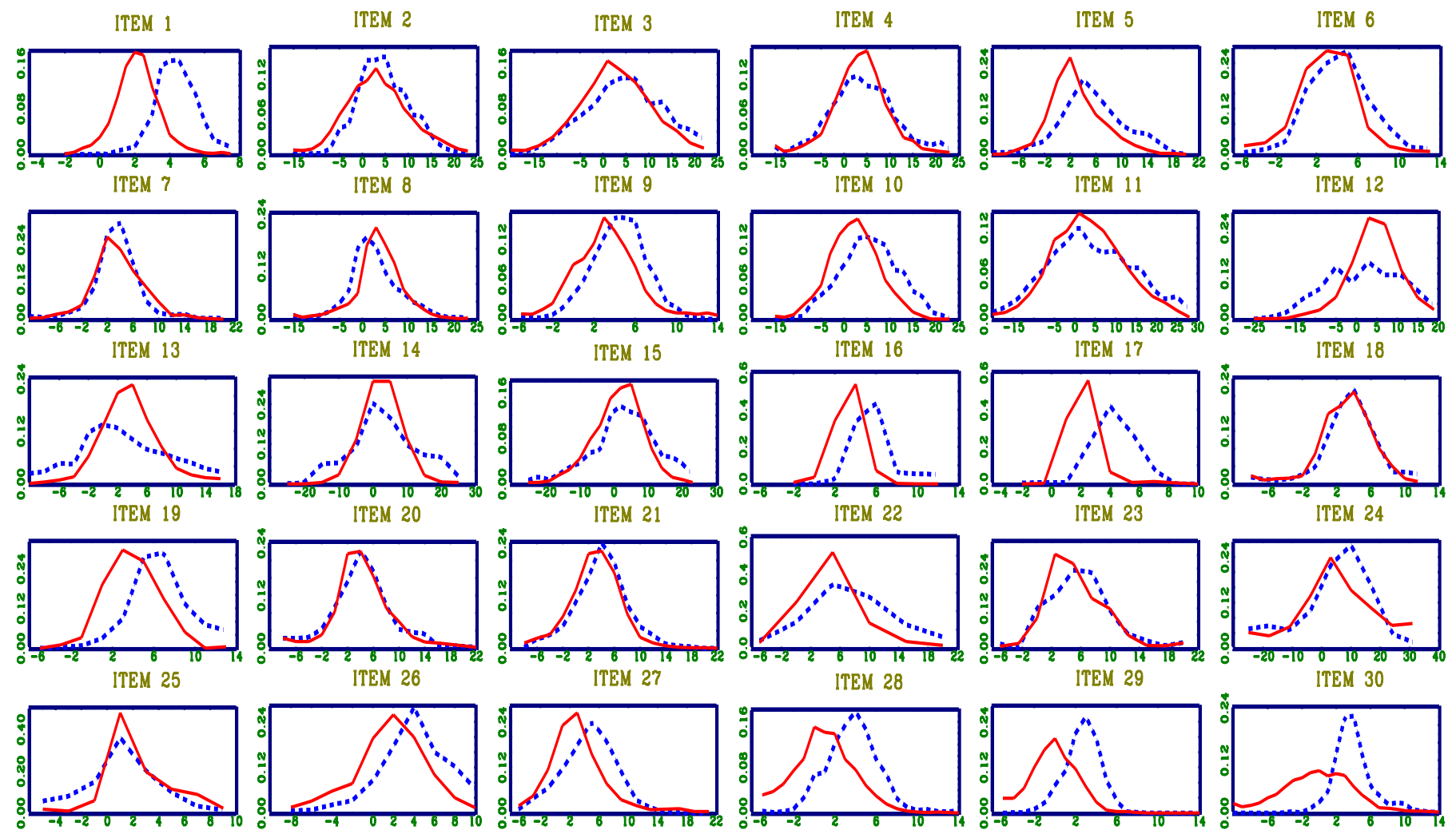

ITEM 28
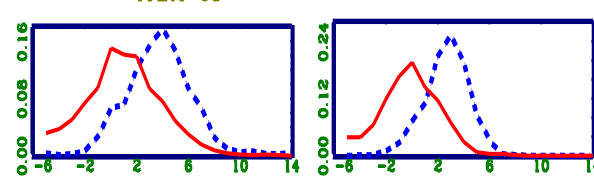

ITEM 30

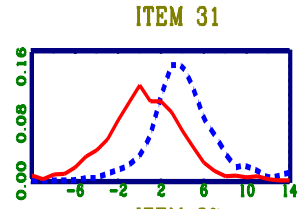

ITEM 32

ITEM 33
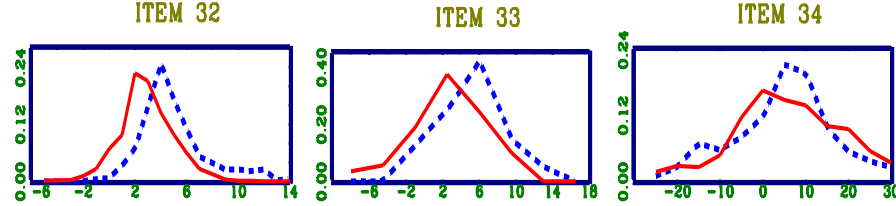

ITEM 35

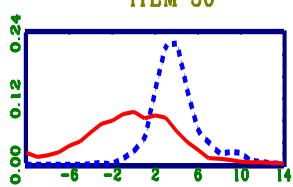

ITEM 3

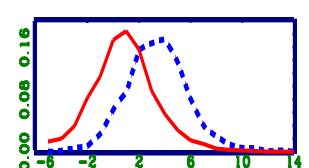

ITEM 39
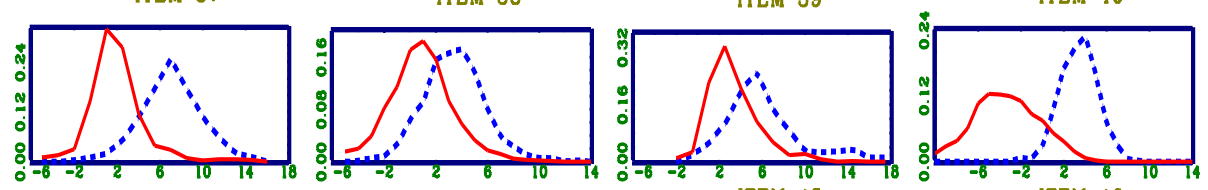

ITEM 45 ITEM 46

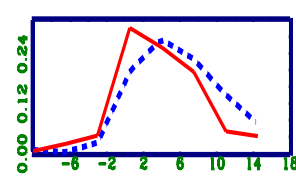

ITEM 41
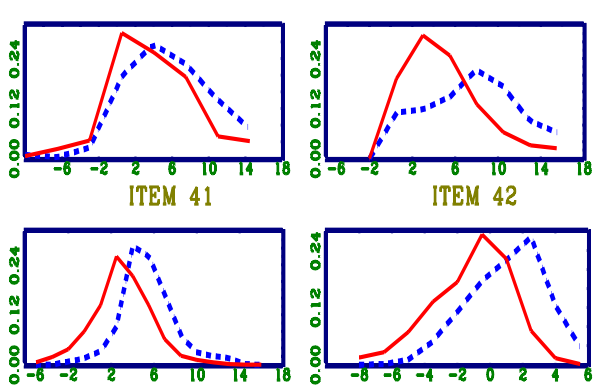

ITEM 47

ITEM 48
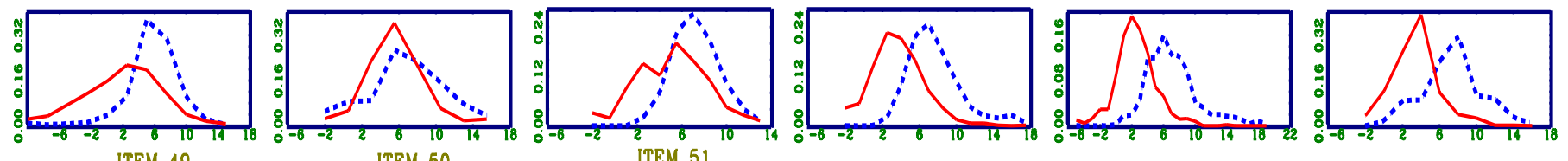

ITEM 49
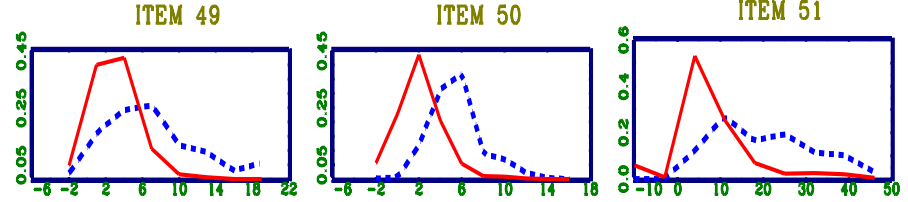

Figure 1: Empirical densities of sectoral inflation before (dotted line) and after (solid line) IT adoption 


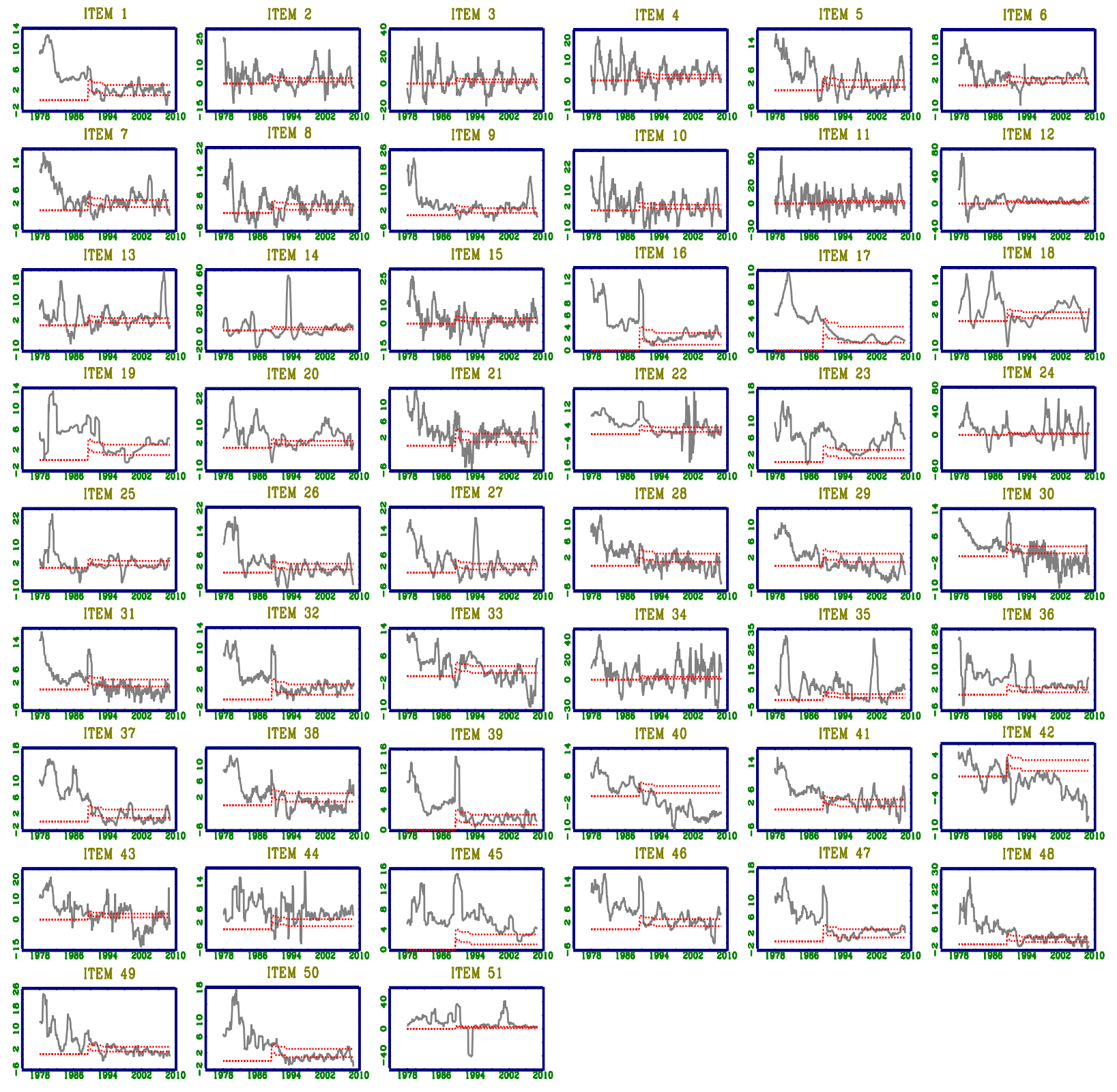

Figure 2: Sectoral inflation (solid line) and target inflation rates (dotted lines) 
NAT
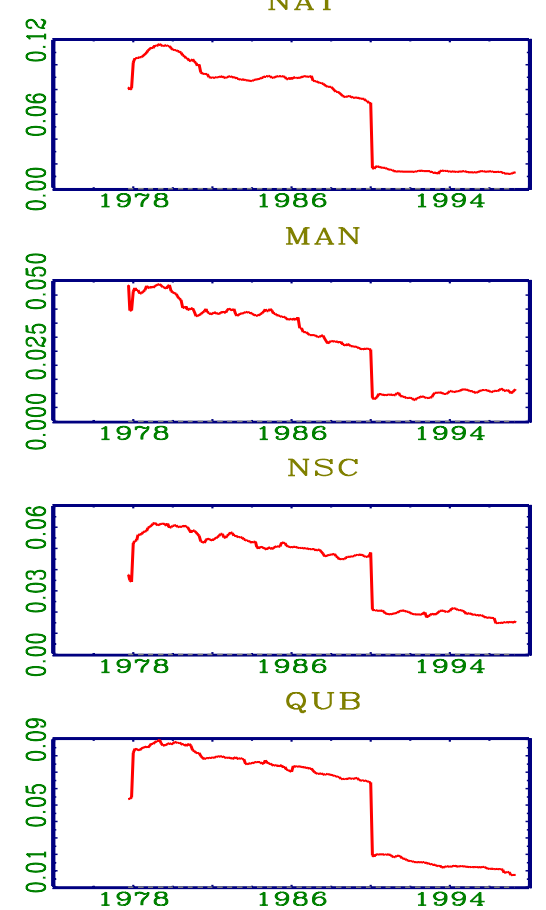

$\mathrm{ALB}$
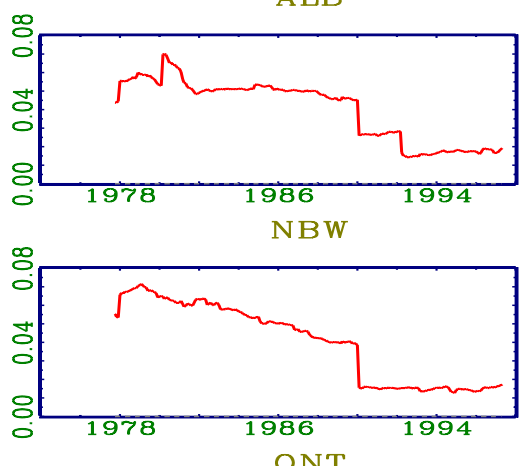

ONT

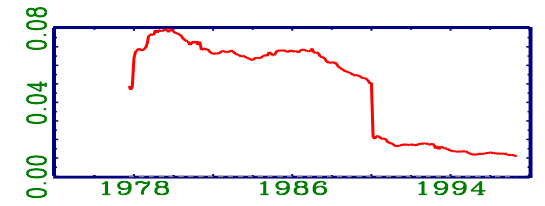

SAS

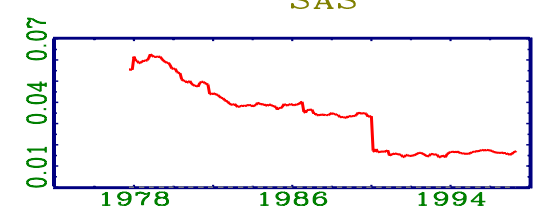

BCA

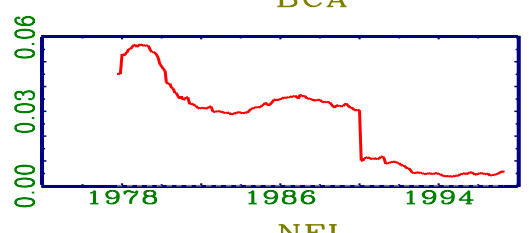

NFL
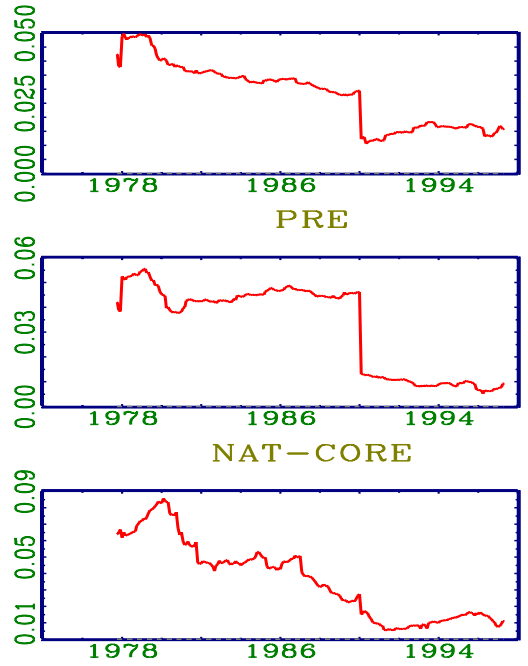

$<$ Cross-sector correlation by provinces $>$

ITEM 1 - Overall
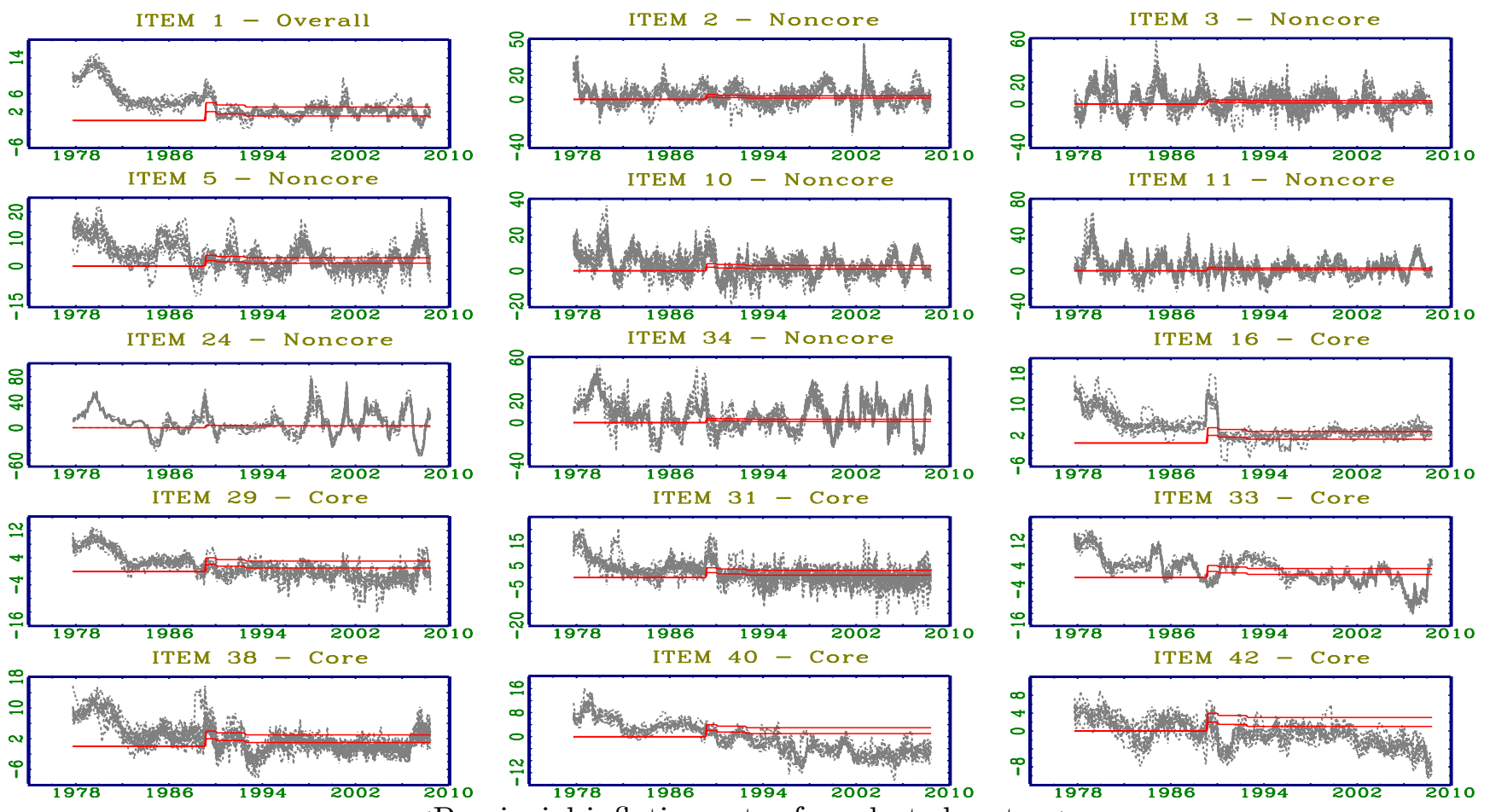

Figure 3: Provincial inflation and cross-sector correlation 

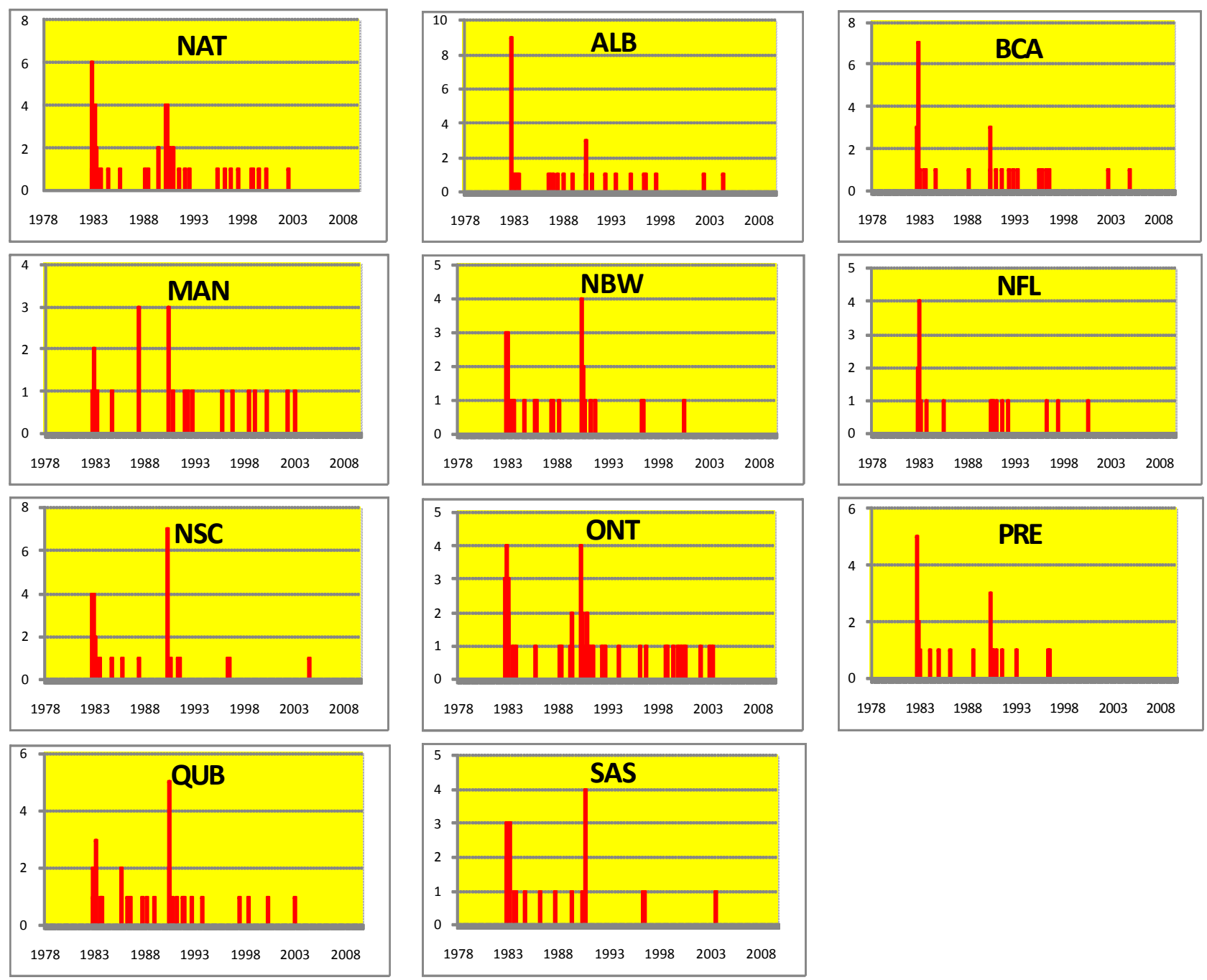

Figure 4: Frequency of estimated breakpoints 

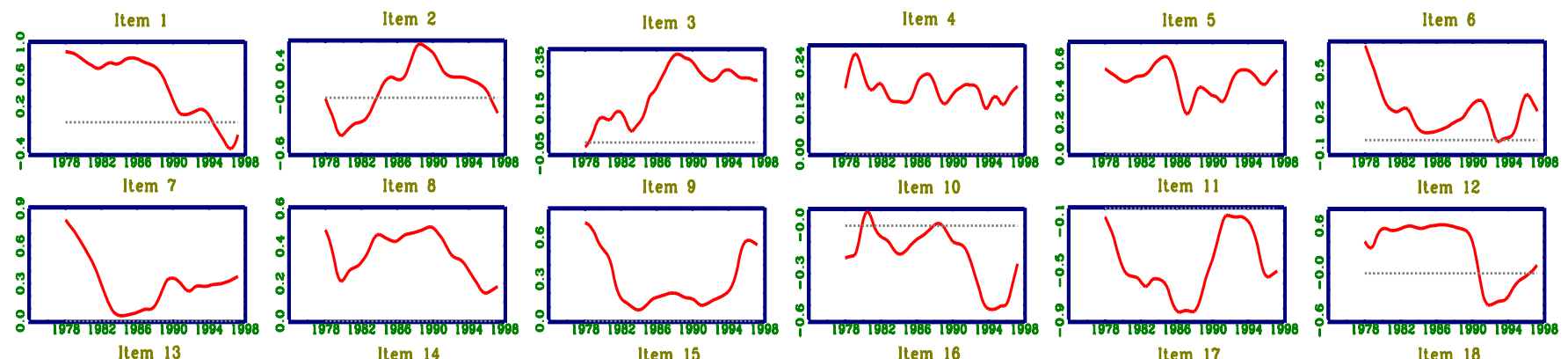

Item 11

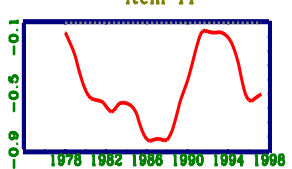

Item 12

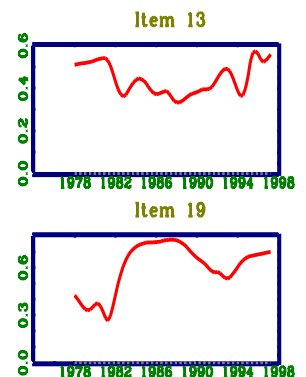

Item 14

Item 16

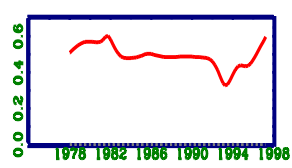

Item 15
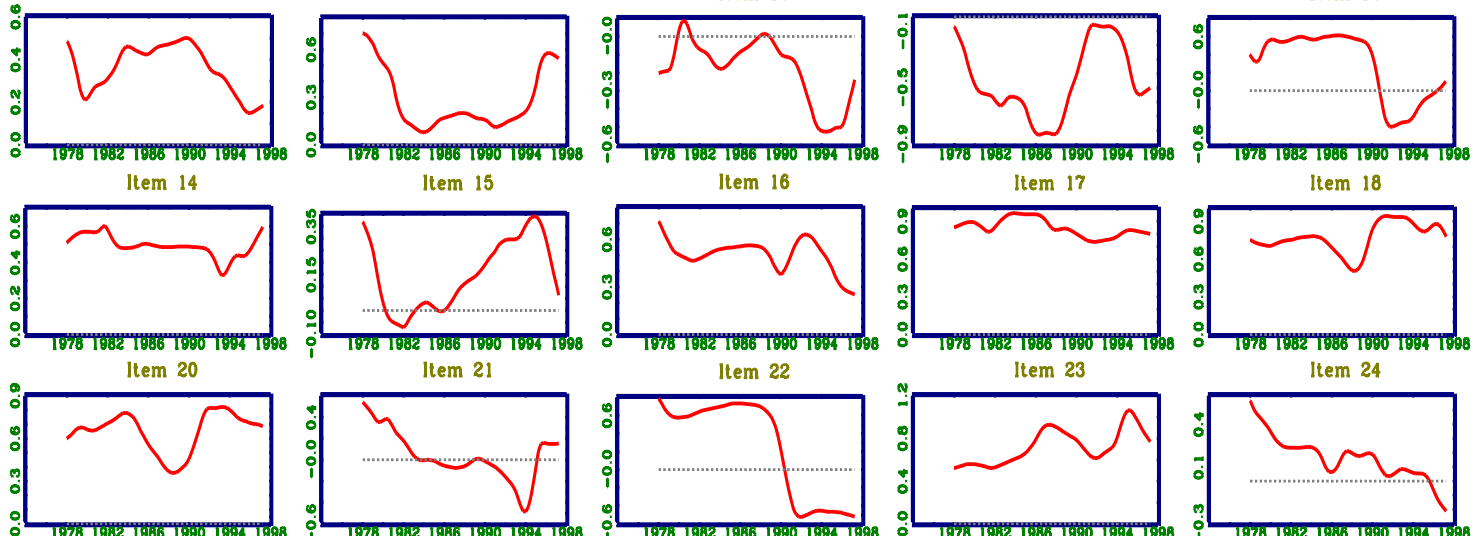

Item 21

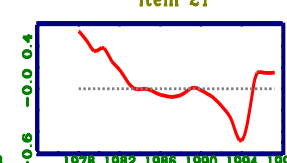

Item 22
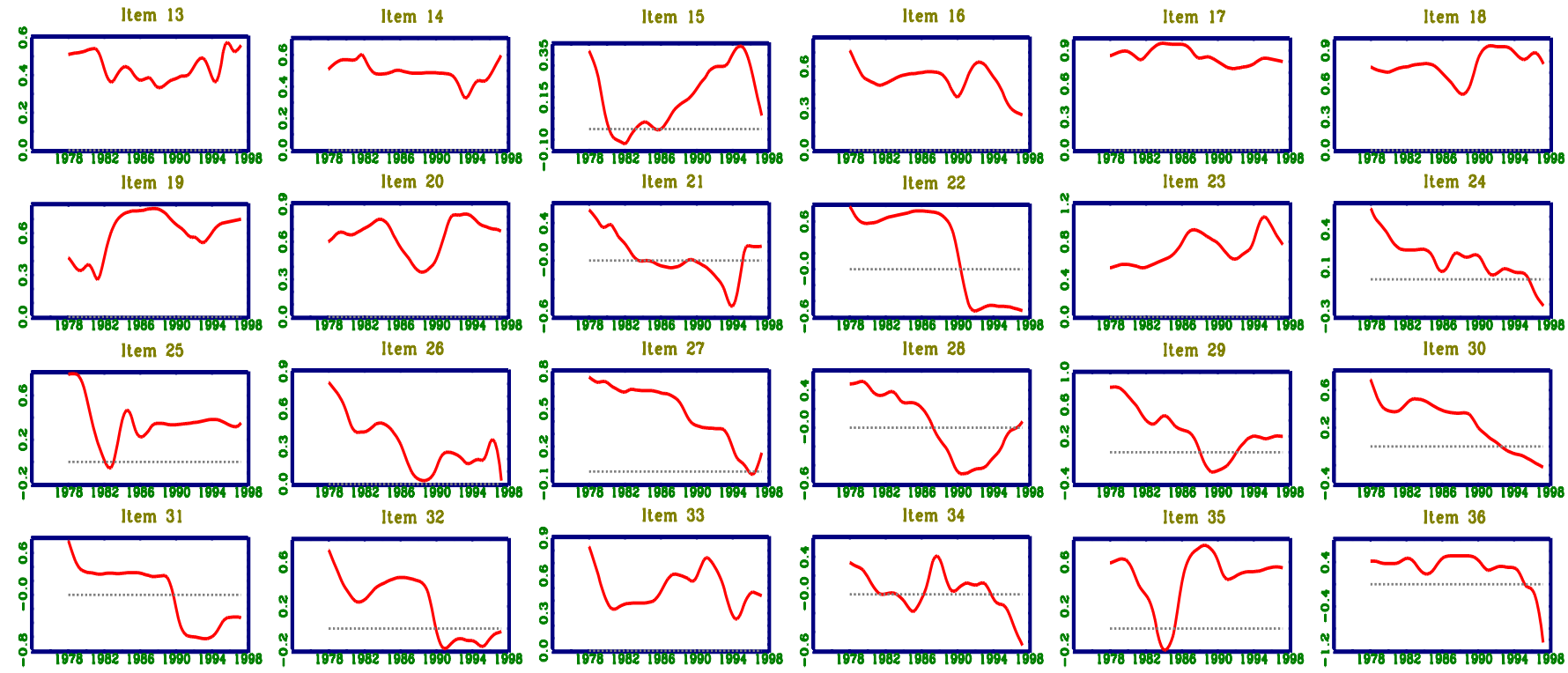

Item 32
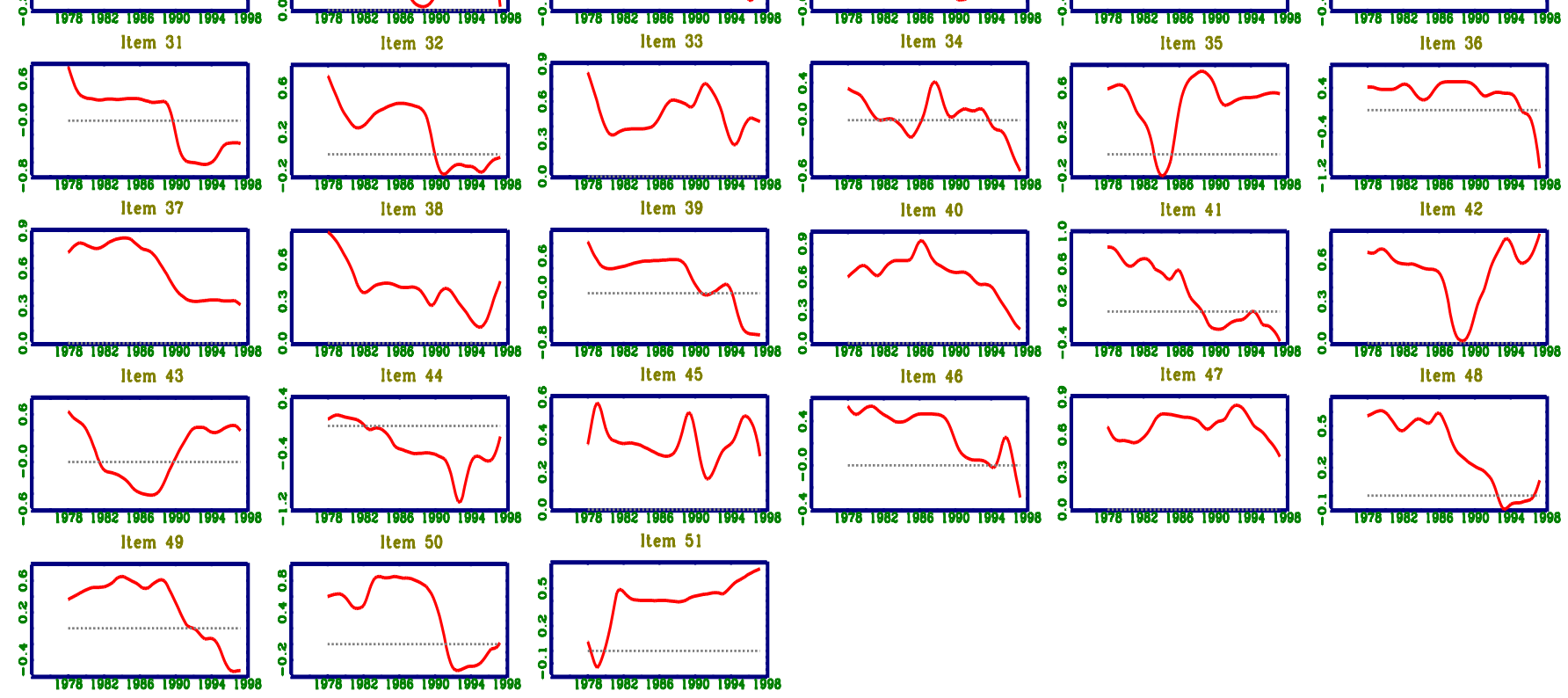

Figure 5: Persistence of inflation by sector - 12 year rolling window 

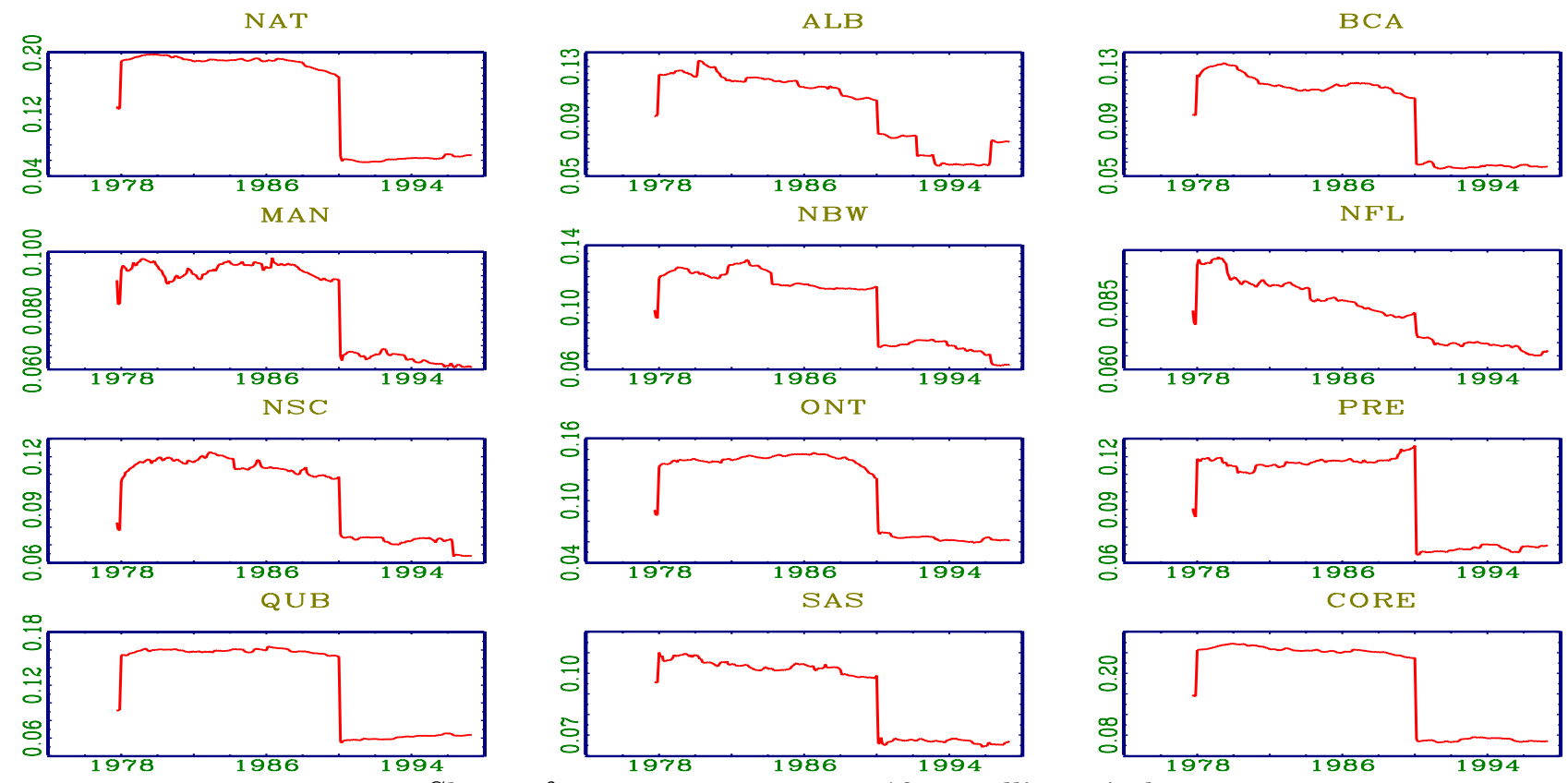

$<$ Share of common component:12-yr rolling window $>$
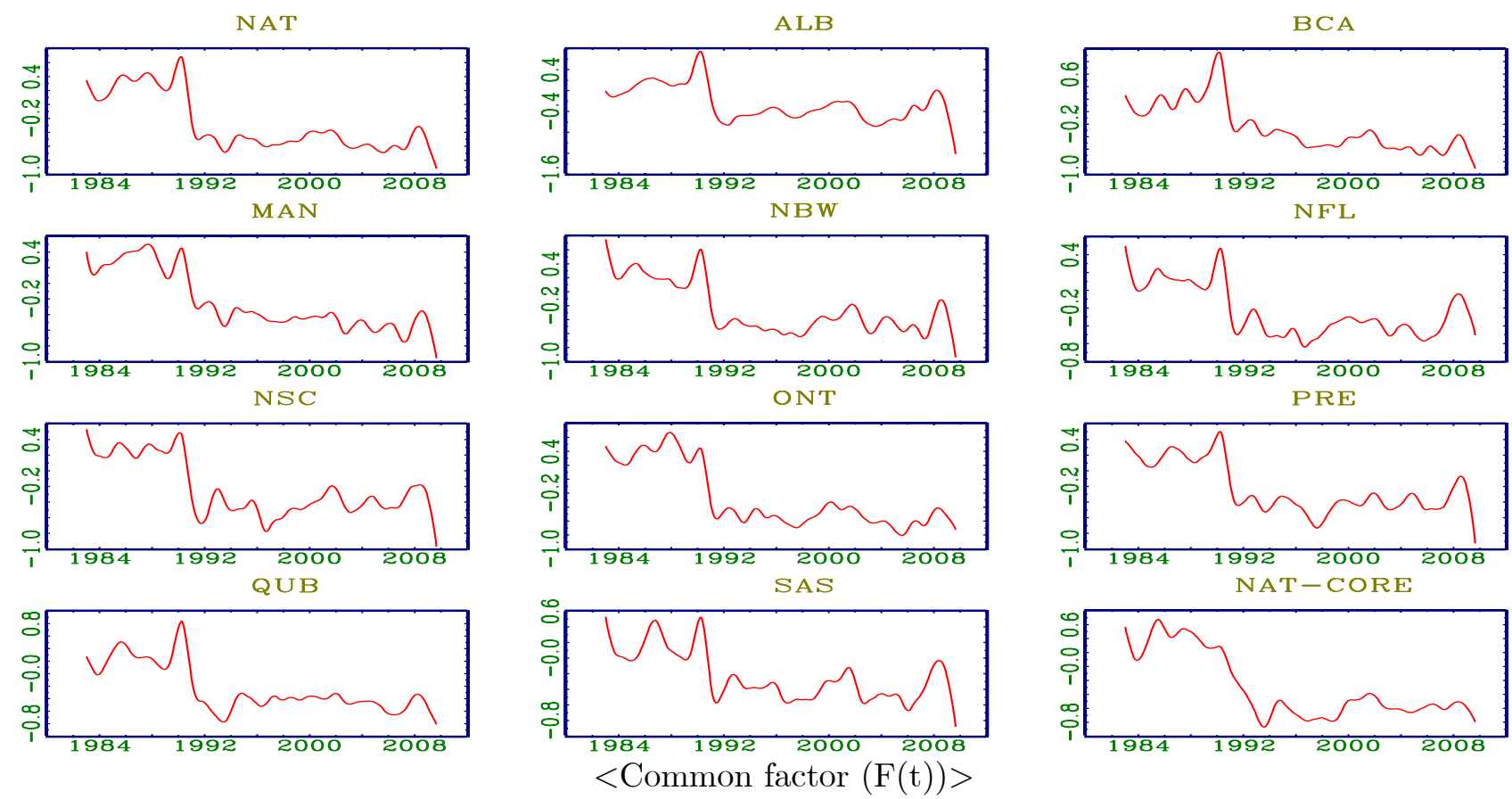

Figure 6: Share of common component and common factor 


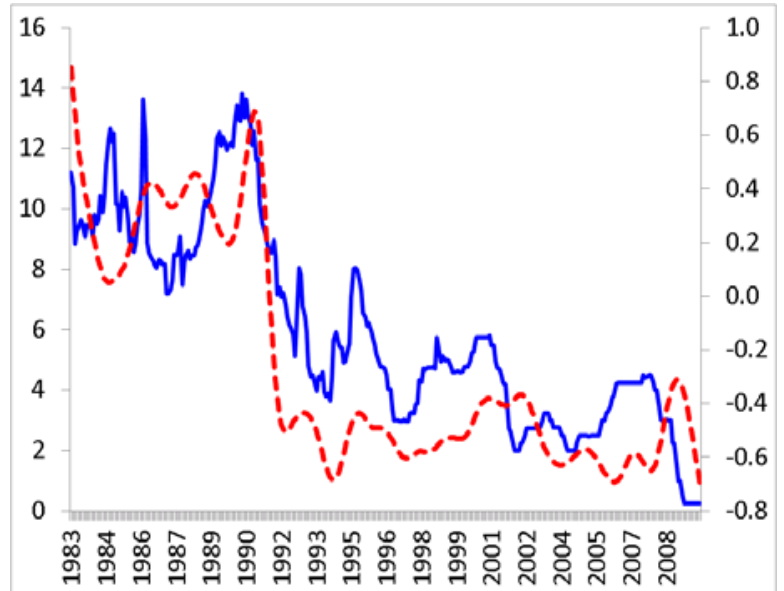

$<$ Short-term interest rate $>$
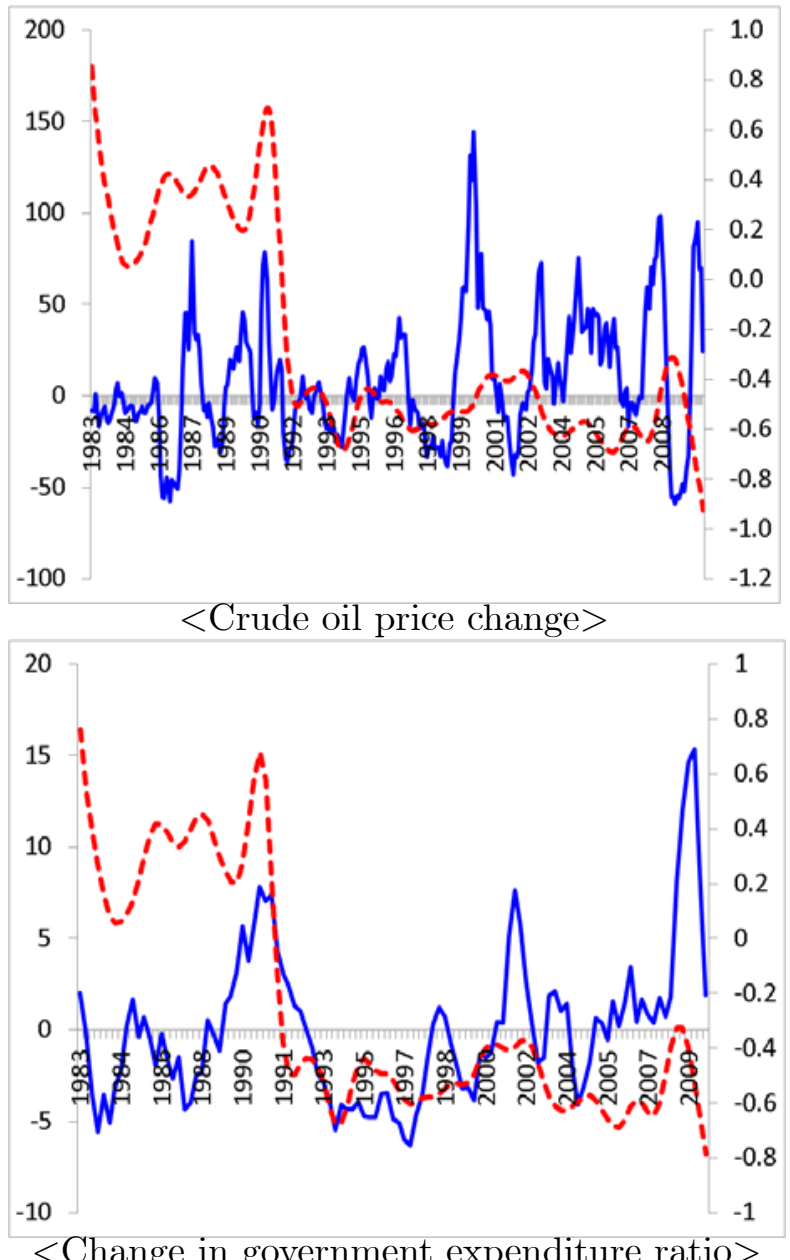
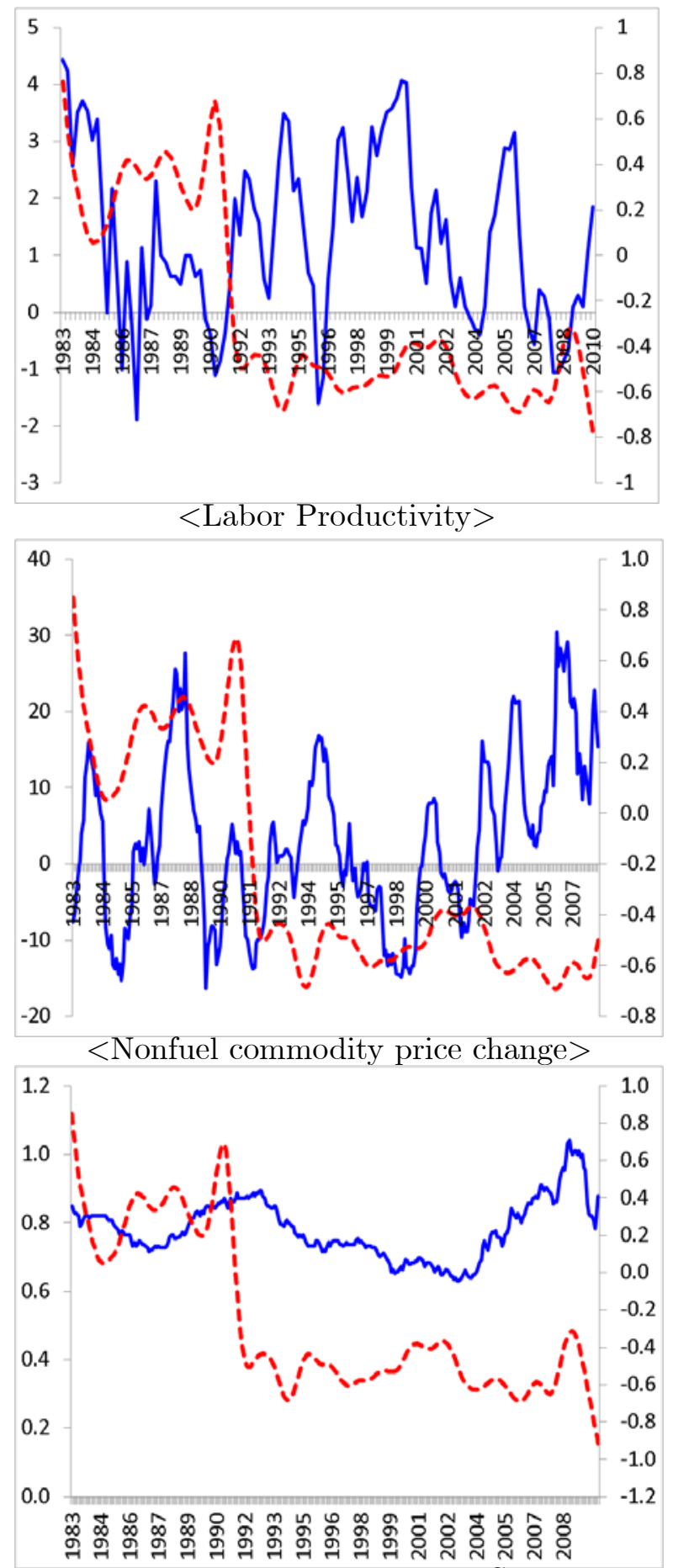

$<$ Exchange rate against USD $>$

Figure 7: Common factor (red dotted) and aggregate shocks (blue solid) 

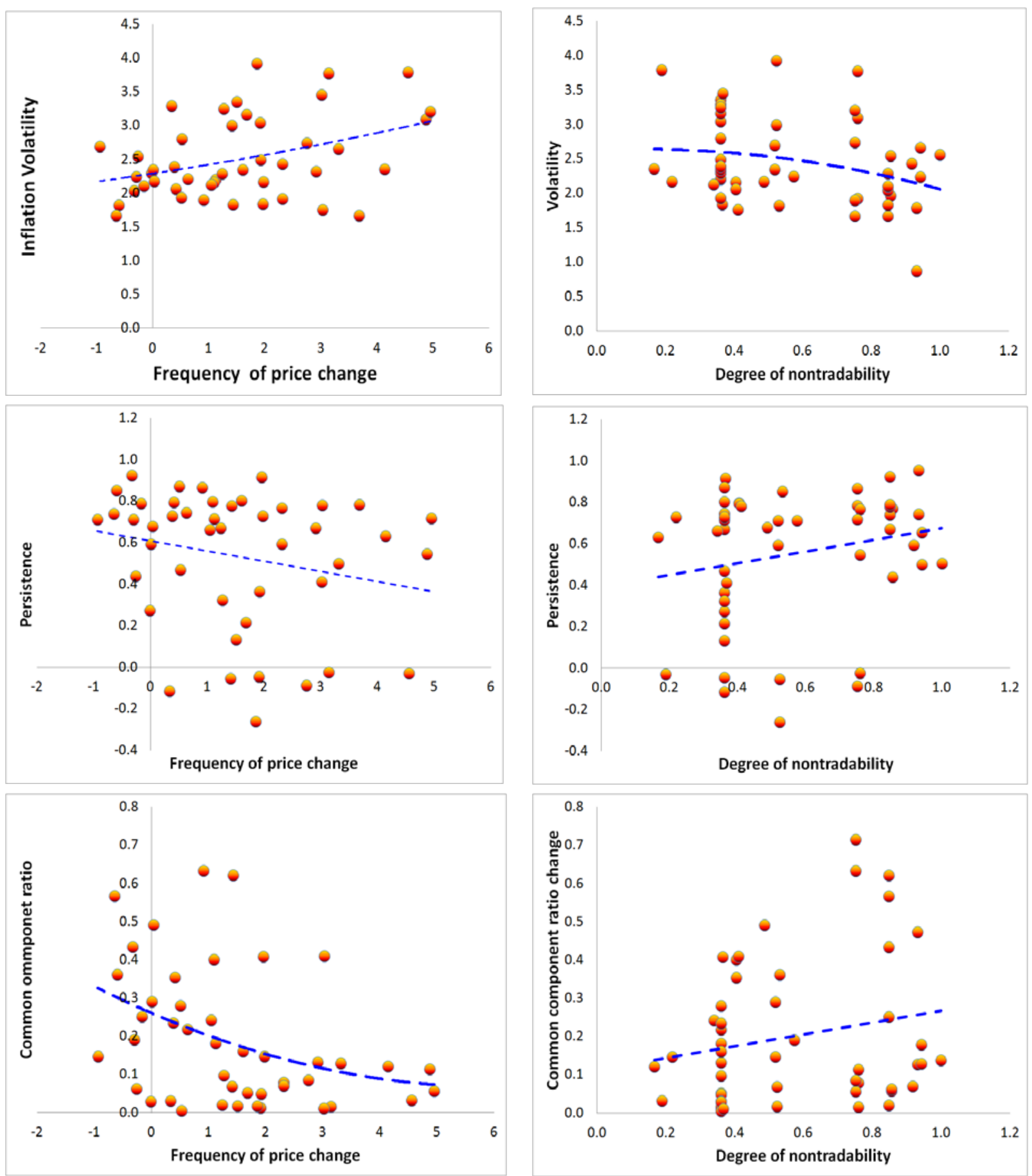

Figure 8: The association of price flexibility (left) and nontradability (right) with various dynamics of sector 